ARTICLE

\title{
SARS-CoV-2-specific T cell memory is sustained in COVID-19 convalescent patients for 10 months with successful development of stem cell-like memory $T$ cells
}

Jae Hyung Jung ${ }^{1,6}$, Min-Seok Rha (10 1,2,6, Moa Sa (1) 1,3, Hee Kyoung Choi ${ }^{4}$, Ji Hoon Jeon ${ }^{4}$, Hyeri Seok ${ }^{4}$, Dae Won Park ${ }^{4}$, Su-Hyung Park (10) ${ }^{1,3}$, Hye Won Jeong (i) ${ }^{5 凶}$, Won Suk Choi (i) ${ }^{4 凶}$ \& Eui-Cheol Shin (i) ${ }^{1,3 凶}$

\begin{abstract}
Memory $T$ cells contribute to rapid viral clearance during re-infection, but the longevity and differentiation of SARS-CoV-2-specific memory $T$ cells remain unclear. Here we conduct ex vivo assays to evaluate SARS-CoV-2-specific CD4+ ${ }^{+}$and CD8 ${ }^{+} \mathrm{T}$ cell responses in COVID19 convalescent patients up to 317 days post-symptom onset (DPSO), and find that memory $T$ cell responses are maintained during the study period regardless of the severity of COVID19. In particular, we observe sustained polyfunctionality and proliferation capacity of SARSCoV-2-specific T cells. Among SARS-CoV-2-specific CD4 ${ }^{+}$and $\mathrm{CD} 8^{+} \mathrm{T}$ cells detected by activation-induced markers, the proportion of stem cell-like memory $T$ ( $T_{S C M}$ ) cells is increased, peaking at approximately 120 DPSO. Development of $\mathrm{T}_{\text {SCM }}$ cells is confirmed by SARS-CoV-2-specific MHC-I multimer staining. Considering the self-renewal capacity and multipotency of $\mathrm{T}_{\mathrm{SCM}}$ cells, our data suggest that SARS-CoV-2-specific T cells are longlasting after recovery from COVID-19, thus support the feasibility of effective vaccination programs as a measure for COVID-19 control.
\end{abstract}

\footnotetext{
${ }^{1}$ Graduate School of Medical Science and Engineering, Korea Advanced Institute of Science and Technology (KAIST), Daejeon, Republic of Korea. ${ }^{2}$ Department of Otorhinolaryngology, Yonsei University College of Medicine, Seoul, Republic of Korea. ${ }^{3}$ The Center for Epidemic Preparedness, KAIST, Daejeon, Republic of Korea. ${ }^{4}$ Division of Infectious Diseases, Department of Internal Medicine, Korea University College of Medicine, Ansan Hospital, Ansan, Republic of Korea. ${ }^{5}$ Department of Internal Medicine, Chungbuk National University College of Medicine, Cheongju, Republic of Korea. ${ }^{6}$ These authors contributed equally: Jae Hyung Jung, Min-Seok Rha. ${ }^{凶}$ email: hwjeong@chungbuk.ac.kr; cmcws@korea.ac.kr; ecshin@kaist.ac.kr
} 
S evere acute respiratory syndrome coronavirus 2 (SARSCoV-2) infection causes coronavirus disease 2019 (COVID19), an ongoing pandemic disease that threatens public health ${ }^{1}$. As of May 2, 2021, more than 150 million confirmed cases had been reported, and over 3 million deaths worldwide ${ }^{2}$. After SARS-CoV-2 infection, some patients, particularly elderly patients, develop severe COVID-19 that is associated with hyperinflammatory responses ${ }^{3,4}$. Global efforts are underway to prevent the transmission of SARS-CoV-2 and to develop novel vaccines and therapeutic strategies. A thorough understanding of the immune responses against SARS-CoV-2 is urgently needed to control the COVID-19 pandemic.

Increasing evidence has demonstrated that SARS-CoV-2specific memory $\mathrm{T}$ cell responses are elicited after recovery from COVID-19. A number of studies have reported SARS-CoV2 -specific memory $\mathrm{T}$ cell responses in the early convalescent phase of COVID-195-9. SARS-CoV-2-specific CD4 ${ }^{+}$and CD8 ${ }^{+}$ $\mathrm{T}$ cells have been detected in $100 \%$ and $~ 70 \%$ of convalescent individuals a short time after resolution ${ }^{5}$. Recently, memory $\mathrm{T}$ cells were shown to contribute to protection against SARSCoV-2 re-challenge in a rhesus macaque model ${ }^{10}$. Considering that $\mathrm{T}$ cell responses to SARS-CoV-1 and Middle East respiratory syndrome coronavirus (MERS-CoV) are long-lasting, up to $>17$ years ${ }^{6,11-13}$, SARS-CoV-2-specific memory T cells are expected to be maintained long-term and to contribute to rapid viral clearance during re-infection. A very recent study has examined SARS-CoV-2-specific $\mathrm{T}$ cell responses up to 8 months after infection using activation-induced marker (AIM) assays ${ }^{14}$.

Following natural infection or vaccination, the generation of effective and persistent $\mathrm{T}$ cell memory is essential for long-term protective immunity to the virus. Among diverse memory $\mathrm{T}$ cell subsets, stem cell-like memory $\mathrm{T}\left(\mathrm{T}_{\mathrm{SCM}}\right)$ cells were recently reported to have the capacity for self-renewal and multipotency to repopulate the broad spectrum of memory and effector $\mathrm{T}$ cell subsets ${ }^{15,16}$. Thus, the successful generation of $\mathrm{T}_{\mathrm{SCM}}$ cells is required for long-term protective $\mathrm{T}$ cell immunity ${ }^{16}$. For example, long-lived memory $\mathrm{T}$ cells following vaccination with liveattenuated yellow fever virus (YFV) exhibit stem cell-like properties and mediate lifelong protection ${ }^{17,18}$. However, limited knowledge is available on the differentiation of SARS-CoV-2specific memory $\mathrm{T}$ cells following recovery from COVID-19, particularly the generation of $\mathrm{T}_{\mathrm{SCM}}$ cells.

In the present study, we report SARS-CoV-2-specific CD4 ${ }^{+}$ and $\mathrm{CD} 8{ }^{+} \mathrm{T}$ cell responses in peripheral blood mononuclear cells (PBMCs) from individuals infected with SARS-CoV-2 over 10 months post-infection. Using diverse $\mathrm{T}$ cell assays, we show that SARS-CoV-2-specific memory $\mathrm{T}$ cell responses are maintained 10 months after the infection. In addition, we report the differentiation of SARS-CoV-2-specific memory $\mathrm{T}$ cells during the study period and the successful generation of $\mathrm{T}_{\mathrm{SCM}}$ cells. We also demonstrate the effector functions and the proliferation capacity of long-term memory $\mathrm{CD}^{+}$and $\mathrm{CD}^{+}{ }^{+} \mathrm{T}$ cells. Our findings provide insights for understanding long-term SARSCoV-2-specific $\mathrm{T}$ cell immunity.

\section{Results}

Study cohort. We recruited 101 individuals with SARS-CoV-2 infection. The peak disease severity was evaluated according to the NIH severity of illness categories ${ }^{19}$ : asymptomatic $(n=7)$, mild $(n=46)$, moderate $(n=25)$, severe $(n=14)$, and critical $(n$ $=9)$. Whole blood samples were obtained longitudinally (2-4 time points) from 56 patients or at a single time point from 45 patients. Whole blood was collected 1-317 days post-symptom onset (DPSO). Finally, a total of 193 PBMC samples were analyzed. Among 193 PBMC samples, 37 samples were obtained in the acute phase when viral RNA was still detected (1-33 DPSO), and 156 samples were obtained in the convalescent phase after the negative conversion of viral RNA (31-317 DPSO). In the current study, we defined the acute phase as 1-30 DPSO, and the convalescent phase as 31-317 DPSO. The demographic and clinical characteristics of enrolled patients are presented in Supplementary Table 1 . The proportion of patients with asymptomatic, mild, moderate, severe, and critical diseases at T1 (31-99 DPSO), T2 (100-199 DPSO), and T3 ( $\geq 200$ DPSO) is presented in Supplementary Table 2. Details of the blood samples used in each assay are summarized in Supplementary Data 1.

SARS-CoV-2-specific T cell responses are sustained 10 months after the infection. First, we performed direct ex vivo interferon$\gamma($ IFN- $\gamma$ ) enzyme-linked immunospot (ELISpot) assays following stimulation of PBMCs with overlapping peptide (OLP) pools spanning the spike $(\mathrm{S})$, membrane $(\mathrm{M})$, and nucleocapsid $(\mathrm{N})$ proteins of SARS-CoV-2. S-, M-, and N-specific IFN- $\gamma$ spot numbers increased during the acute phase. Subsequently, there was a decreasing tendency until 60-120 DPSO, and the IFN- $\gamma$ responses were maintained over 10 months (Fig. 1a). These kinetics were also observed when S-, M-, and N-specific IFN- $\gamma$ spot numbers were summed (Fig. 1a). In each PBMC sample, all three OLP pools evenly contributed to the IFN- $\gamma$ responses without antigen dominance (Fig. 1b). We divided convalescent samples into three groups based on the DPSO at sample collection: T1 (31-99 DPSO), T2 (100-199 DPSO), and T3 ( $\geq 200$ DPSO). We found no significant difference in IFN- $\gamma$ spot numbers among groups (Fig. 1c), and a maintenance of an even contribution of antigens for the IFN- $\gamma$ response among groups (Supplementary Fig. 1). Next, we focused on longitudinally tracked samples from 39 individuals in the convalescent phase. S-, $\mathrm{M}$-, and N-specific and summed IFN- $\gamma$ spot numbers were stable during the convalescent phase (Fig. 1d). When we compared paired samples from the same patient at two-time points (t1, 31100 DPSO; $t 2, \geq 200$ DPSO), we found no significant difference in IFN- $\gamma$ spot numbers (Fig. 1e).

To investigate the SARS-CoV-2-specific $\mathrm{CD}^{+}$and $\mathrm{CD}^{+}{ }^{+} \mathrm{T}$ cell responses separately, we evaluated SARS-CoV-2-specific $\mathrm{T}$ cell responses by AIM assays $5,20,21$ following stimulation of PBMCs with OLP pools of $\mathrm{S}, \mathrm{M}$, and $\mathrm{N}$. $\mathrm{CD} 137^{+} \mathrm{OX} 40^{+}$cells were considered SARS-CoV-2-specific cells among CD4 ${ }^{+} \mathrm{T}$ cells, and $\mathrm{CD} 137^{+} \mathrm{CD} 69^{+}$ cells were considered SARS-CoV-2-specific cells among $\mathrm{CD}^{+}$ $\mathrm{T}$ cells ${ }^{5}$ (Fig. 2a, b). We confirmed a strong positive correlation between the frequency of $\mathrm{CD} 137^{+} \mathrm{OX} 40^{+}$cells and the frequencies of alternative $\mathrm{AIM}^{+}$cells $\left(\mathrm{OX} 40^{+} \mathrm{CD} 154^{+}\right.$or $\mathrm{CD} 137^{+} \mathrm{CD} 154^{+}$cells) among $\mathrm{CD}^{+}{ }^{+} \mathrm{T}$ cells (Supplementary Fig. 2). The frequency of S-, M, and $\mathrm{N}$-specific $\mathrm{CD} 137^{+} \mathrm{OX} 40^{+}$cells among $\mathrm{CD} 4^{+} \mathrm{T}$ cells increased during the acute phase, decreased until 60 DPSO, and then was maintained over 10 months (Fig. 2c). When the frequency of S-, M-, and $\mathrm{N}$-specific $\mathrm{CD} 137^{+} \mathrm{OX} 40^{+}$cells was summed, similar kinetics were observed (Fig. 2c). The frequency of $\mathrm{CD} 137^{+} \mathrm{CD} 69^{+}$cells among $\mathrm{CD}^{+} \mathrm{T}$ cells was relatively low compared to the frequency of

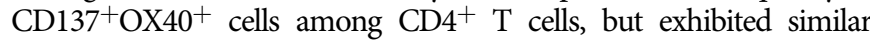
kinetics (Fig. 2c). We also observed a positive correlation between the frequency of $\mathrm{CD} 137^{+} \mathrm{OX} 40^{+}$cells among $\mathrm{CD} 4^{+} \mathrm{T}$ cells and the frequency of $\mathrm{CD} 137^{+} \mathrm{CD} 69^{+}$cells among $\mathrm{CD}^{+} \mathrm{T}$ cells (Supplementary Fig. 3).

We also measured the level of SARS-CoV-2 S receptor-binding domain (RBD)-specific IgG antibodies and SARS-CoV-2 neutralizing activity in plasma samples from COVID-19 convalescent patients. We found that the level of RBD-specific antibodies decreased over time, whereas the level of neutralizing activity was maintained (Supplementary Fig. 4a). In statistical analysis of time points T1 (31-99 DPSO), T2 (100-199 DPSO), and T3 ( $\geq 200$ 
a

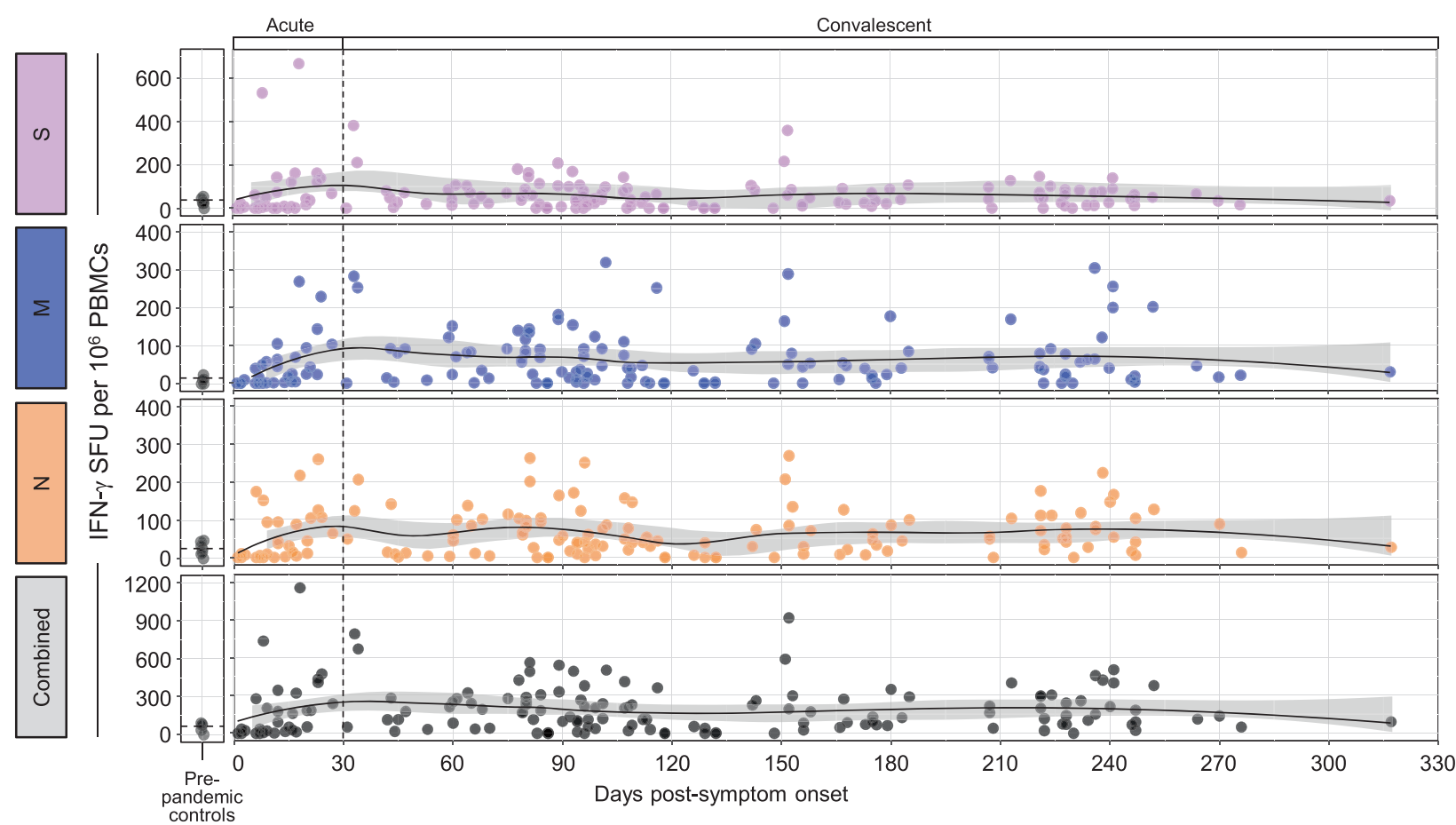

b

$\square \mathrm{S} \square \mathrm{M} \square \mathrm{N}$

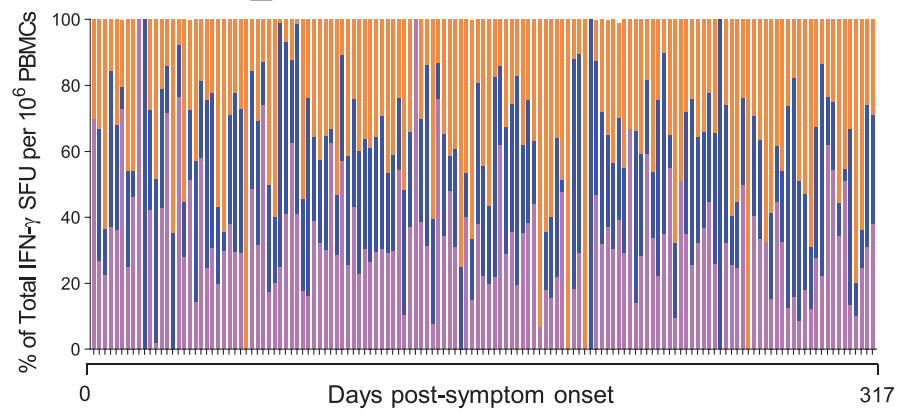

d

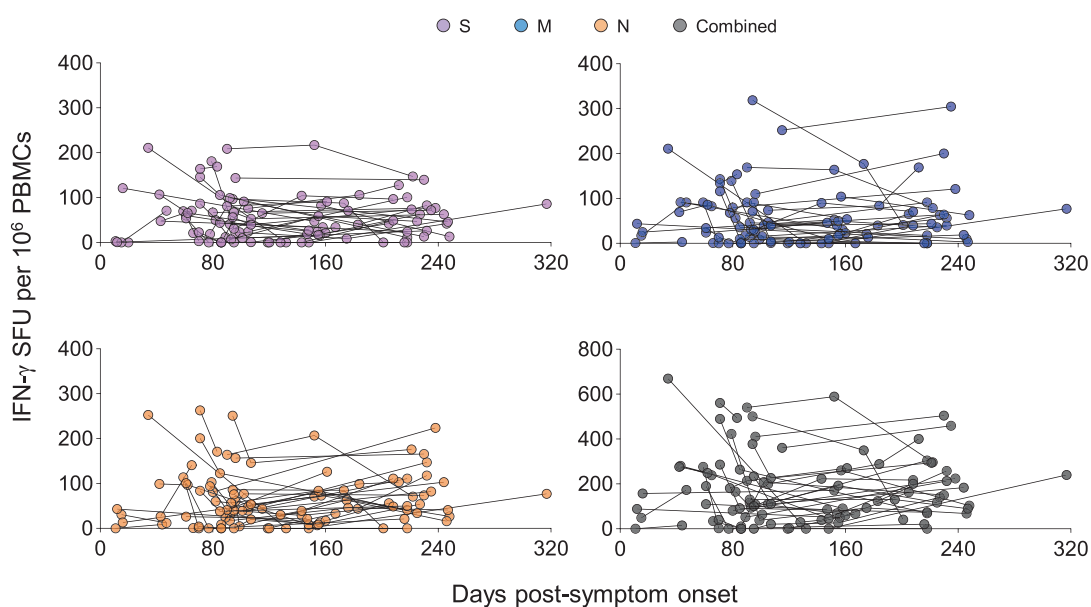

C

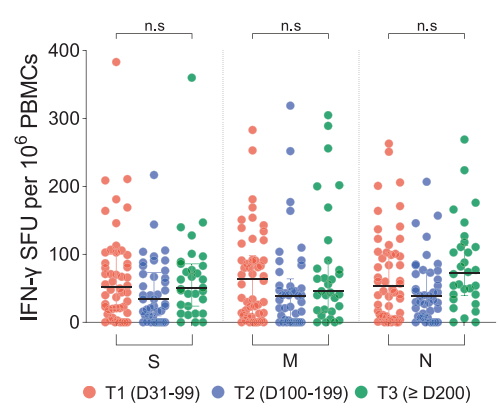

e

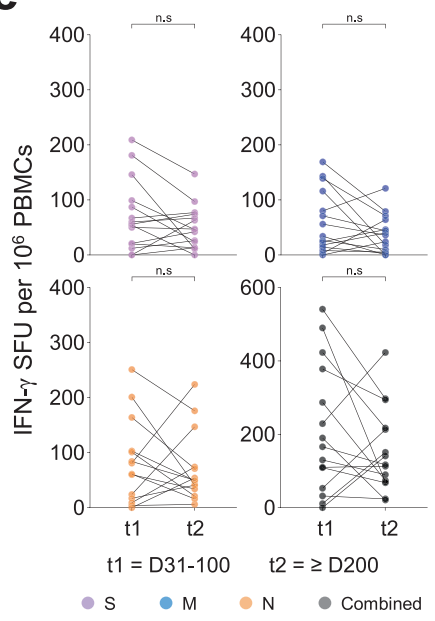

Fig. 1 SARS-CoV-2-specific IFN- $\boldsymbol{\gamma}$ responses over 10 months post-infection. PBMC samples $(n=159)$ from individuals with SARS-CoV-2 infection $(n=$ $87)$ and pre-pandemic PBMC samples $(n=8)$ from healthy donors $(n=8)$ were stimulated with OLPs of $S, M$, or $N(1 \mu \mathrm{g} / \mathrm{mL})$ for $24 \mathrm{~h}$ and the spotforming units of IFN- $\gamma$-secreting cells examined by ELISpot. a Scatter plots showing the relationship between DPSO and IFN- $\gamma$ responses. The black line is a LOESS smooth nonparametric function, and the gray shading represents the $95 \%$ confidence interval. $\mathbf{b}$ The composition of S-, M-, or N-specific IFN- $\gamma$ responses among the total IFN- $\gamma$ responses in each individual. c IFN- $\gamma$ responses were compared between T1 $(n=49,31-99$ DPSO), T2 $(n=41,100-199$ DPSO), and T3 ( $n=31, \geq 200$ DPSO). Data are presented as median and interquartile range (IQR). d, e IFN- $\gamma$ responses were analyzed in longitudinally tracked samples $(n=103)$ from 39 individuals. d Scatter plots showing the relationship between DPSO and IFN- $\gamma$ responses. e IFN- $\gamma$ responses were compared between paired samples at two-time points ( $n=15 ; \mathrm{t} 1,31-100$ DPSO; t2, $\geq 200$ DPSO). Statistical analysis was performed using the two-sided Kruskal-Wallis test with Dunns' multiple comparisons test (c) or the Wilcoxon signed-rank test (e). n.s, not significant. 
a

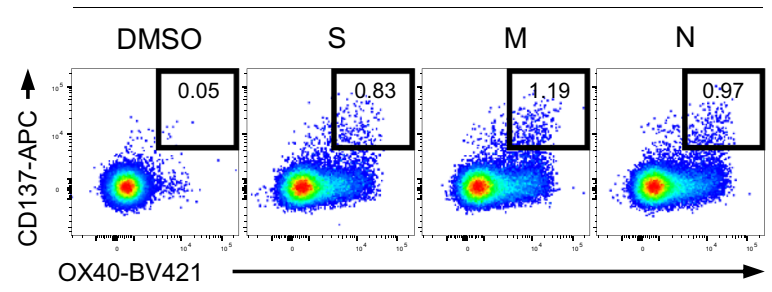

C
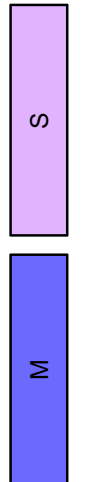

$z$
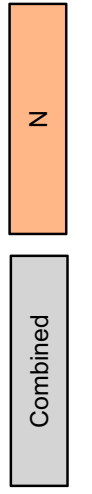

$\mathrm{CD}^{+} \mathrm{T}$ cells
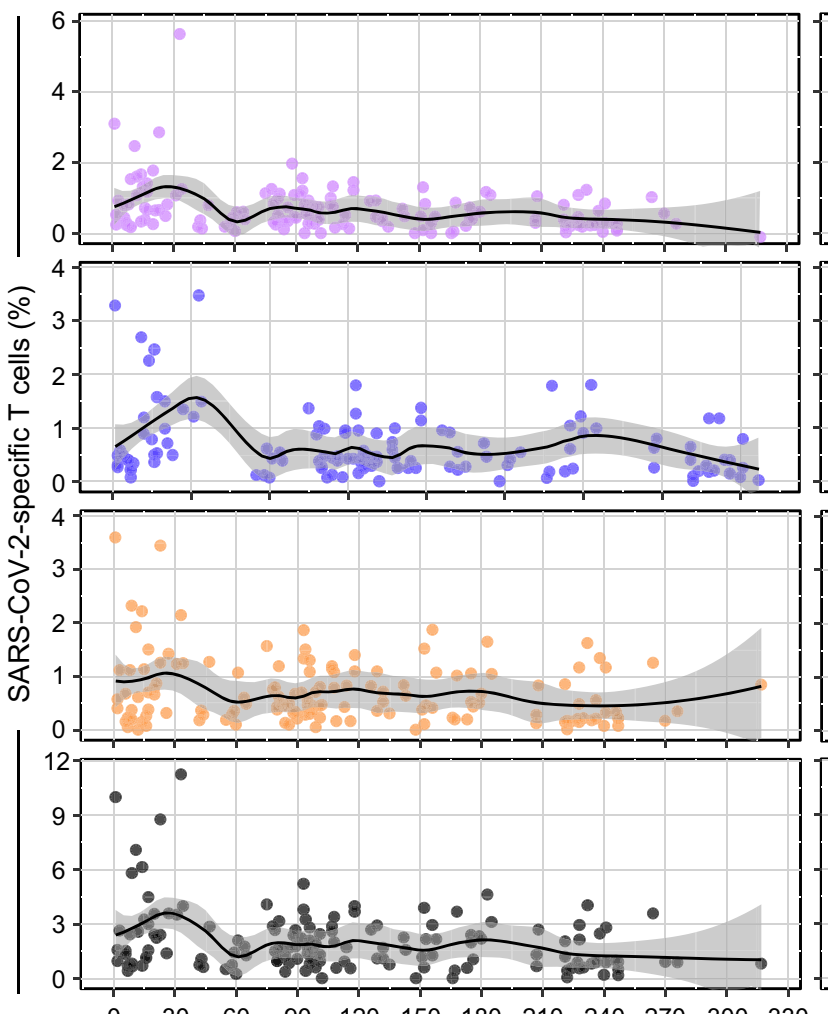

b

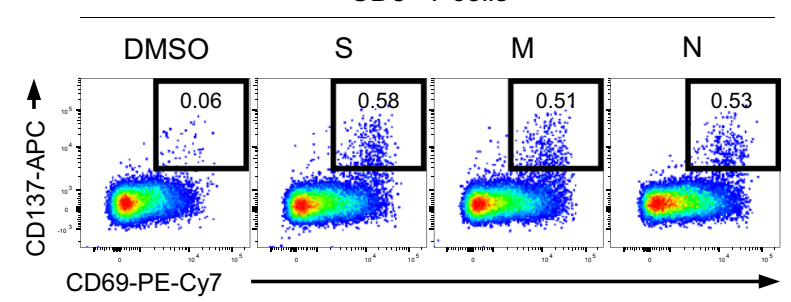

$\mathrm{CD}^{+} \mathrm{T}$ cells
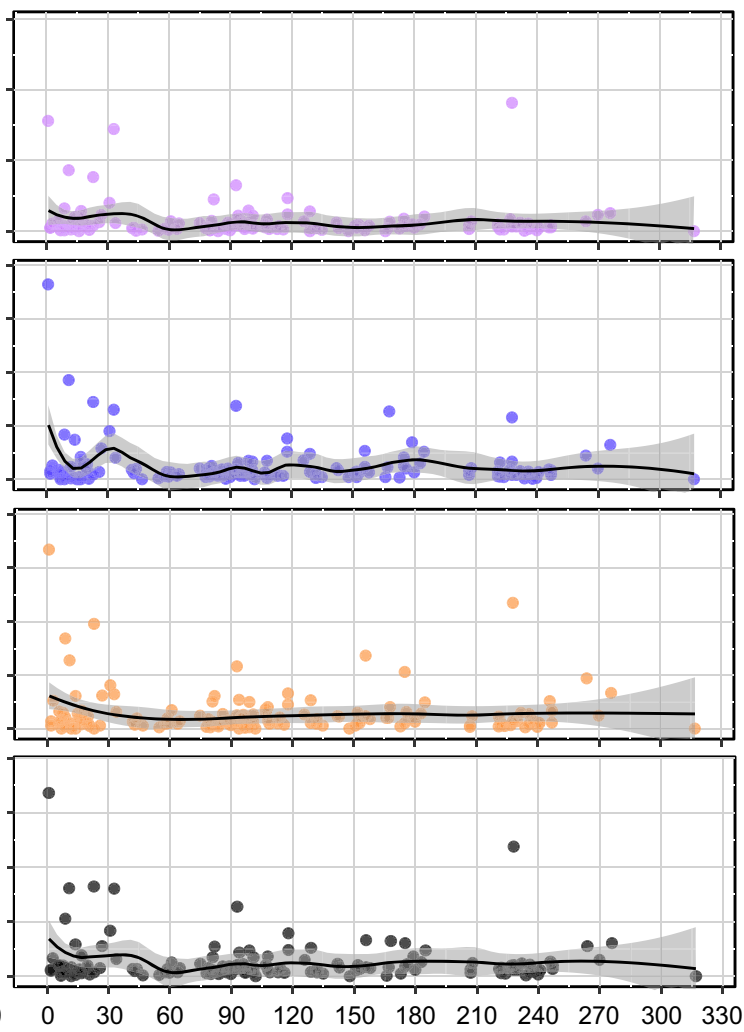

Days post-symptom onset

Fig. 2 Kinetics of SARS-CoV-2-specific activation-induced marker (AIM) $+\mathbf{T}$ cells. PBMC samples $(n=146)$ from individuals with SARS-CoV-2 infection $(n=82)$ were stimulated with OLPs of $\mathrm{S}, \mathrm{M}$, or $\mathrm{N}(1 \mu \mathrm{g} / \mathrm{mL})$ for $24 \mathrm{~h}$. The frequency of $\mathrm{AIM}^{+}\left(\mathrm{CD}_{137^{+}} \mathrm{OXX}_{40^{+}}\right)$cells among CD4 ${ }^{+} \mathrm{T}$ cells and the frequency of $\mathrm{AlM}^{+}\left(\mathrm{CD}_{3} 7^{+} \mathrm{CD} 9^{+}\right)$cells among $\mathrm{CD}^{+}{ }^{+}$cells were analyzed. Representative flow cytometry plots showing the frequency of $\mathrm{AlM}^{+}$cells among $\mathrm{CD} 4^{+}$ (a) or $\mathrm{CD}^{+}$(b) T cells. c Scatter plots showing the relationship between DPSO and the frequency of $\mathrm{AIM}^{+}$cells among CD4+ (left) or CD8 ${ }^{+}$(right) T cells. The black is a LOESS smooth nonparametric function, and the gray shading represents the $95 \%$ confidence interval.

DPSO), the level of RBD-specific antibodies significantly decreased but the level of neutralizing activity did not (Supplementary Fig. 4b). We did not observe a significant correlation between long-term ( $\geq 200$ DPSO) SARS-CoV-2specific $\mathrm{T}$ cell responses as evaluated by IFN- $\gamma$ ELISpot and AIM assays and antibody levels (Supplementary Fig. 4c, d). Collectively, these results indicate that SARS-CoV-2-specific T cell responses are long-lasting over 10 months in COVID-19 convalescent patients although SARS-CoV-2-specific antibody response may decrease.

SARS-CoV-2-specific $\mathrm{T}_{\mathrm{SCM}}$ cells develop after the infection. Next, we examined the differentiation status of SARS-CoV-2-specific $\mathrm{AIM}^{+} \mathrm{T}$ cells based on CCR7 and CD45RA expression in CD4 ${ }^{+}$ (Fig. 3a) and $\mathrm{CD}^{+}$(Fig. 3b) T cell populations. Among SARS-CoV2-specific $\mathrm{AIM}^{+} \mathrm{CD}^{+}{ }^{+} \mathrm{T}$ cells, the proportion of $\mathrm{CCR} 7^{+} \mathrm{CD} 45 \mathrm{RA}^{-}$ $\left(\mathrm{T}_{\mathrm{CM}}\right)$ cells was maintained at approximately $50 \%$ on average during the study period, and the proportion of CCR7 ${ }^{-} \mathrm{CD} 4 \mathrm{RA}{ }^{-}\left(\mathrm{T}_{\mathrm{EM}}\right)$ cells increased up to $\sim 35 \%$ on average until 60 DPSO and then maintained thereafter (Fig. 3c). CCR7 ${ }^{-} \mathrm{CD} 45 \mathrm{RA}^{+}{ }^{-} \mathrm{T}_{\mathrm{EMRA}}$ ) cells were a minor population $(<5 \%$; Fig. $3 \mathrm{c})$. Notably, the proportion of CCR7 ${ }^{+}$CD45RA ${ }^{+}$cells, which include both naïve and $\mathrm{T}_{\mathrm{SCM}}$ cells, was $\sim 30 \%$ on average in the acute phase, decreasing to $\sim 10 \%$ on average by 60 DPSO and then maintained thereafter (Fig. 3c).

Among SARS-CoV-2-specific $\mathrm{AIM}^{+} \mathrm{CD}{ }^{+} \mathrm{T}$ cells, the proportion of $\mathrm{CCR}^{+}{ }^{+} \mathrm{CD} 45 \mathrm{RA}^{-}\left(\mathrm{T}_{\mathrm{CM}}\right)$ cells was $\sim 20 \%$ on average in the acute phase and gradually decreased during the study period (Fig. 3d). The proportion of $\mathrm{CCR}^{-} \mathrm{CD}^{-} 4 \mathrm{RA}^{-}\left(\mathrm{T}_{\mathrm{EM}}\right)$ cells increased up to $50 \%$ on average until 60 DPSO and was maintained thereafter (Fig. 3d). The proportion of CCR7 ${ }^{-} \mathrm{CD}^{4} 5 \mathrm{RA}^{+}\left(\mathrm{T}_{\text {EMRA }}\right)$ cells and $\mathrm{CCR}^{+}{ }^{+} \mathrm{CD} 45 \mathrm{RA}^{+}$cells was maintained $(\sim 25 \%$ and $25-35 \%$ on average, respectively) during the study period (Fig. $3 \mathrm{~d}$ ).

We further investigated whether CCR7 ${ }^{+} \mathrm{CD} 45 \mathrm{RA}^{+}$cells include $\mathrm{T}_{\mathrm{SCM}}$ cells, which have a self-renewal capacity and multipotency for differentiation into diverse $\mathrm{T}$ cell subsets, by examining CD95, a marker of $\mathrm{T}_{\mathrm{SCM}}$ cells ${ }^{15,16}$. In both $\mathrm{AIM}^{+} \mathrm{CD} 4^{+}$and $\mathrm{AIM}^{+} \mathrm{CD} 8^{+}$ 

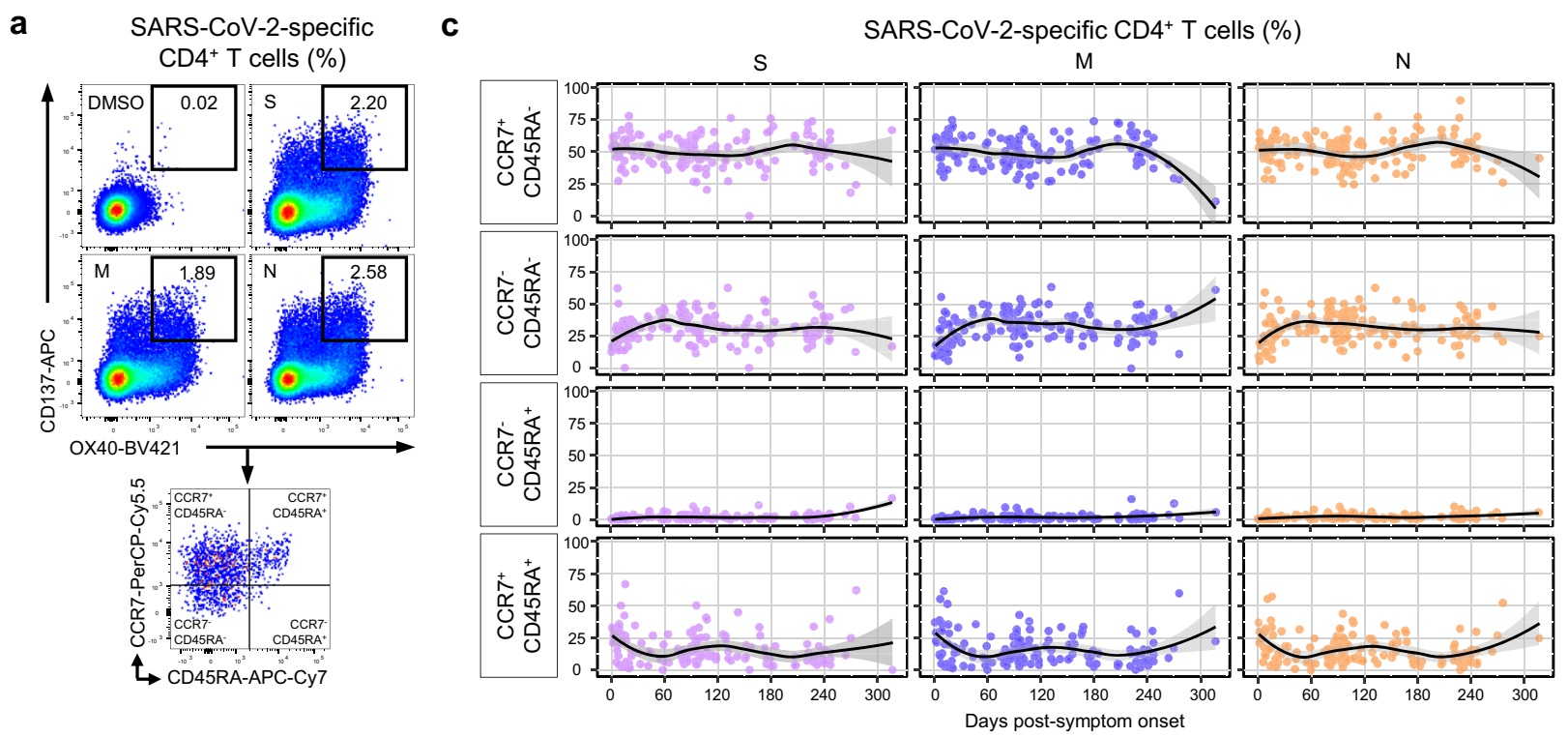

b

d

SARS-CoV-2-specific CD8 ${ }^{+} \mathrm{T}$ cells $(\%)$
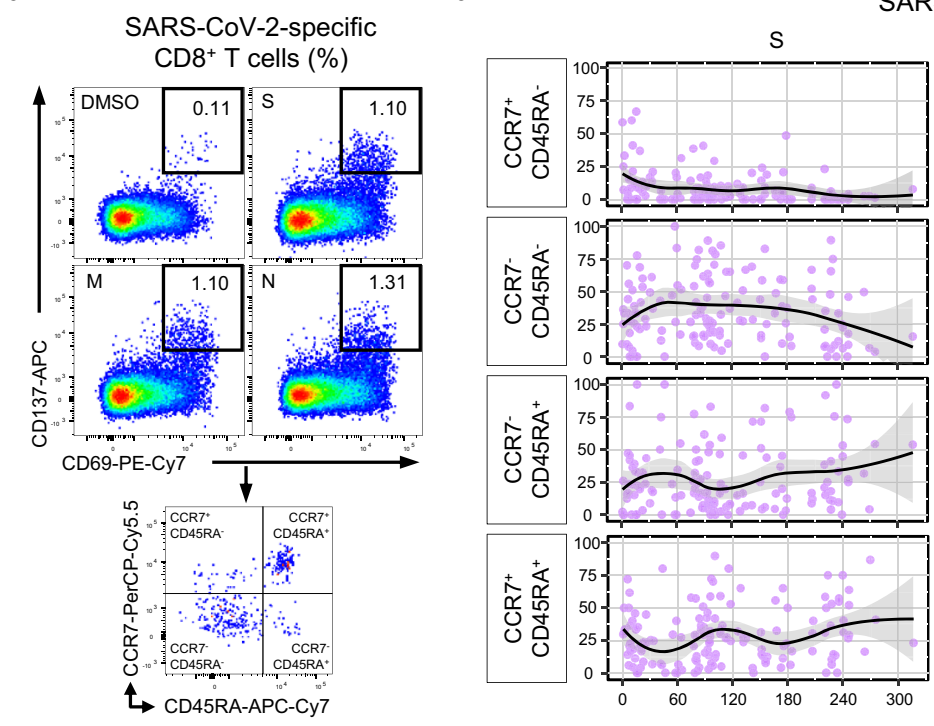

SARS-CoV-2-specific CD8+ $\mathrm{T}$ cells (\%)

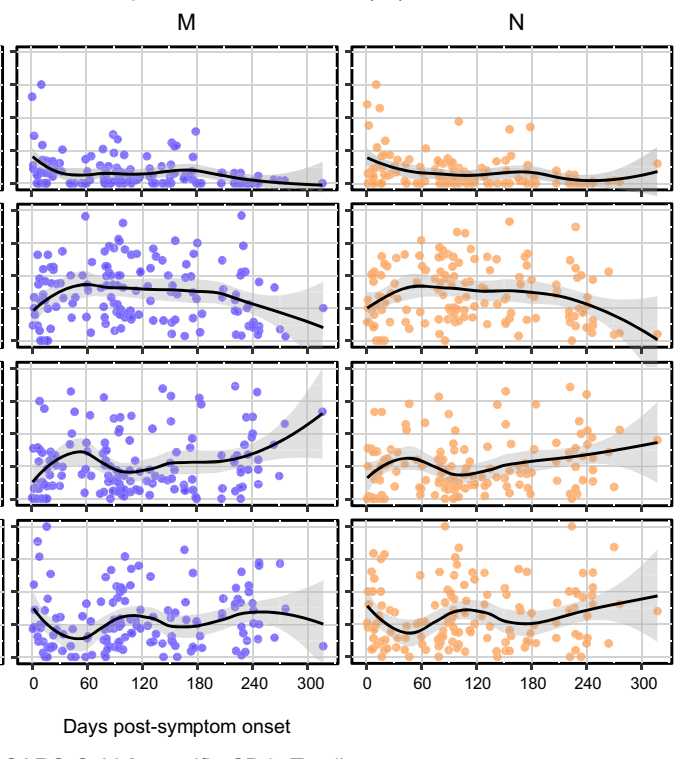

e SARS-CoV-2-specific CD4 ${ }^{+} \mathrm{T}$ cells
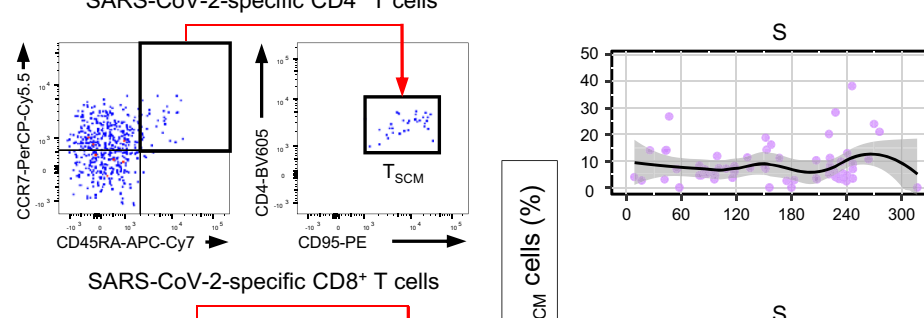

SARS-CoV-2-specific $\mathrm{CD}^{+}{ }^{+} \mathrm{T}$ cells
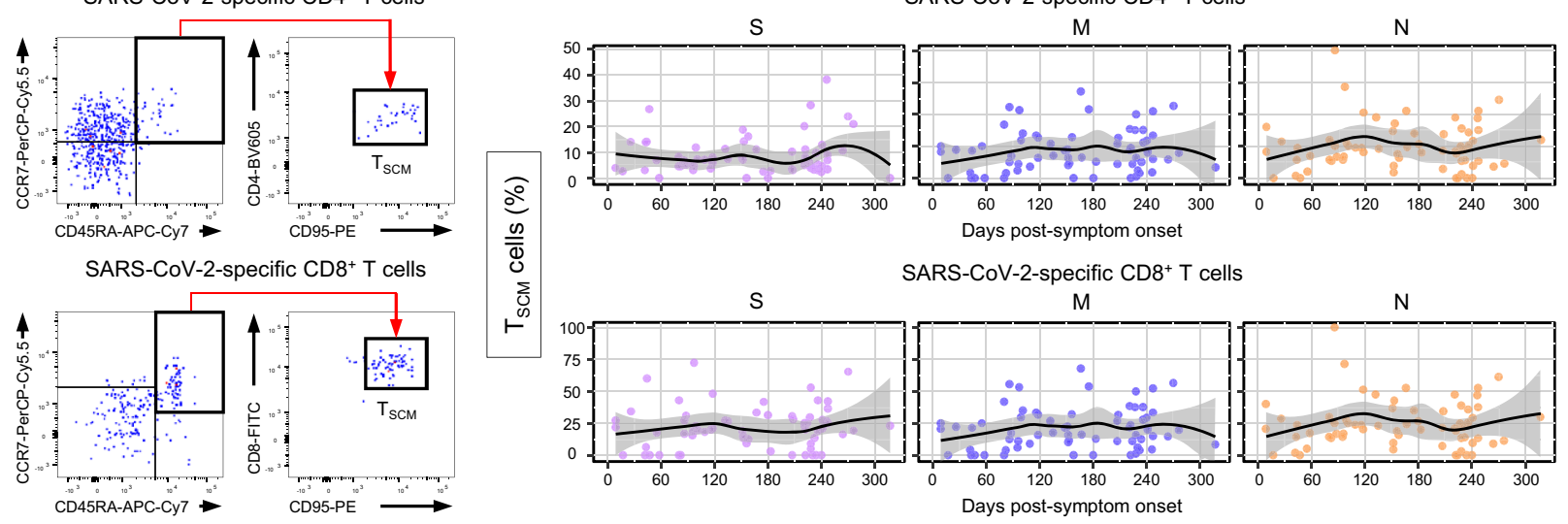

SARS-CoV-2-specific CD8 ${ }^{+} \mathrm{T}$ cells

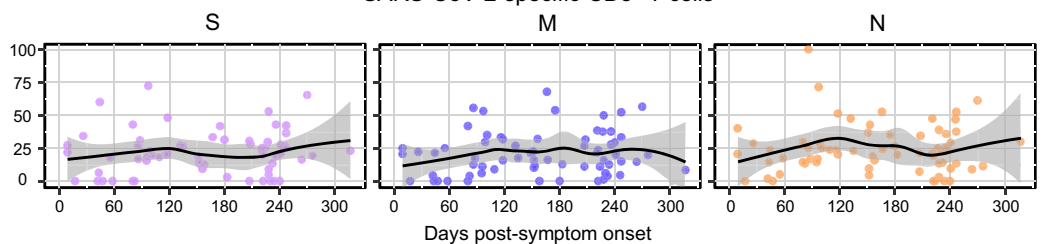

$\mathrm{T}$ cells, $\mathrm{CD}^{+} 5^{+}$cells were a dominant population among CCR7 ${ }^{+}$ $\mathrm{CD}^{2} 5 \mathrm{RA}^{+}$cells (Fig. 3e), indicating that the $\mathrm{CCR}^{+}{ }^{+} \mathrm{CD} 45 \mathrm{RA}^{+}$cells among $\mathrm{AIM}^{+} \mathrm{CD}^{+}$or $\mathrm{AIM}^{+} \mathrm{CD} 8^{+} \mathrm{T}$ cells are mainly $\mathrm{T}_{\mathrm{SCM}}$ cells. The frequency of $\mathrm{T}_{\mathrm{SCM}}$ cells among both $\mathrm{AIM}^{+} \mathrm{CD} 4^{+}$and AIM ${ }^{+} \mathrm{CD}^{+} \mathrm{T}$ cells gradually increased until $120 \mathrm{DPSO}$, when it reached a stable plateau (Fig. 3e). We found no significant difference in the frequency of $\mathrm{T}_{\mathrm{SCM}}$ cells among $\mathrm{AIM}^{+} \mathrm{CD}^{+}$and $\mathrm{AIM}^{+} \mathrm{CD} 8^{+}$ T cells between T1 (31-99 DPSO), T2 (100-199 DPSO), and T3 ( $\geq 200$ DPSO; Supplementary Fig. 5a, b).

Successful development of SARS-CoV-2-specific $\mathrm{T}_{\mathrm{SCM}}$ cells is confirmed by direct ex vivo MHC-I multimer staining. To 
Fig. 3 Differentiation status of SARS-CoV-2-specific AIM $+\mathbf{T}$ cells. a-d PBMC samples $(n=146)$ from individuals with SARS-CoV-2 infection $(n=82)$ were stimulated with OLPs of $\mathrm{S}, \mathrm{M}$, or $\mathrm{N}(1 \mu \mathrm{g} / \mathrm{mL})$ for $24 \mathrm{~h}$ and the expression of CCR7 and CD45RA was analyzed in $\mathrm{AIM}^{+}\left(\mathrm{CD} 137^{+} \mathrm{OX} 40^{+}\right) \mathrm{CD}^{+}(\mathbf{a}, \mathbf{c})$ and $\mathrm{AIM}^{+}\left(\mathrm{CD} 137^{+} \mathrm{CD} 69^{+}\right) \mathrm{CD}^{+}(\mathbf{b}, \mathbf{d}) \mathrm{T}$ cells. Gating strategies for identifying each memory subset among $\mathrm{AIM}^{+} \mathrm{CD} 4^{+}(\mathbf{a})$ or $\mathrm{AIM}^{+} \mathrm{CD} 8^{+}(\mathbf{b}) \mathrm{T}^{\mathrm{c}}$ cells. Scatter plots showing the relationship between DPSO and the proportion of the indicated subsets among AIM $+\mathrm{CD} 4+(\mathbf{c})$ or $\mathrm{AIM}^{+} \mathrm{CD} 8^{+}(\mathbf{d}) \mathrm{T}_{\text {cells. }}$ e PBMC samples $(n=68)$ from COVID-19 convalescent patients $(n=59)$ were stimulated with OLPS of $S, M$, or $N(1 \mu \mathrm{g} / \mathrm{mL})$ for $24 \mathrm{~h}$ and the frequency of $T_{\text {SCM }}$ $\left(\mathrm{CCR} 7+\mathrm{CD} 45 \mathrm{RA}^{+} \mathrm{CD}^{+} 5^{+}\right)$cells was analyzed in $\mathrm{AIM}+\mathrm{CD} 4+$ (upper) and $\mathrm{AIM}+\mathrm{CD} 8+$ (lower) $\mathrm{T}$ cells. Left, The gating strategy for identifying $\mathrm{T}_{\mathrm{SCM}}$ cells. Right, Scatter plots showing the relationship between DPSO and the proportion of $\mathrm{TsCM}_{\mathrm{SC}}$ cells among $\mathrm{AIM}^{+} \mathrm{CD} 4^{+}$or $\mathrm{AIM}^{+} \mathrm{CD} 8^{+} \mathrm{T}$ cells. The black line is a LOESS smooth nonparametric function, and the gray shading represents the $95 \%$ confidence interval $(\mathbf{c}, \mathbf{d}, \mathbf{e})$.

validate the results from in vitro stimulation-based AIM assays, we detected SARS-CoV-2-specific $\mathrm{CD}^{+}{ }^{+} \mathrm{T}$ cells by performing direct ex vivo MHC-I multimer staining and examined the differentiation status of MHC-I multimer+ cells. We used an HLA$\mathrm{A}^{*} 02$ multimer loaded with SARS-CoV-2 $\mathrm{S}_{269}$ (YLQPRTFLL) peptide that has a low degree of homology to the human common cold coronaviruses $(\mathrm{ccCoVs})^{22,23}$. MHC-I multimer ${ }^{+}$cells were detected during the study period until 234 DPSO (Fig. 4a, b), and we determined the proportions of $\mathrm{T}_{\mathrm{CM}}\left(\mathrm{CCR} 7^{+} \mathrm{CD} 45 \mathrm{RA}^{-}\right), \mathrm{T}_{\mathrm{EM}}$ $\left(\mathrm{CCR}^{-}{ }^{-} \mathrm{CD}_{45 \mathrm{RA}^{-}}{ }^{-}\right), \mathrm{T}_{\mathrm{EMRA}}\left(\mathrm{CCR}^{-}{ }^{-} \mathrm{CD} 4 \mathrm{RA}^{+}\right)$, and $\mathrm{T}_{\mathrm{SCM}}$ $\left(\mathrm{CCR} 7^{+} \mathrm{CD} 45 \mathrm{RA}^{+}{ }^{+} \mathrm{CD} 95^{+}\right)$cells among MHC-I multimer ${ }^{+}$cells (Fig. 4c). Influenza A virus (IAV)- and cytomegalovirus (CMV)specific MHC-I multimers were also used to stain PBMCs from healthy donors. Similar to the data from $\mathrm{AIM}^{+} \mathrm{CD} 8^{+} \mathrm{T}$ cells, $\mathrm{T}_{\mathrm{EM}}$ and $\mathrm{T}_{\text {EMRA }}$ cells were the dominant populations among SARSCoV-2-specific MHC-I multimer ${ }^{+}$cells, whereas $\mathrm{T}_{\mathrm{CM}}$ cells were a minor population during the study period (Fig. 4d). Among IAVand CMV-specific MHC-I multimer ${ }^{+}$cells from healthy donors, $\mathrm{T}_{\mathrm{EM}}$ and $\mathrm{T}_{\mathrm{EMRA}}$ cells were dominantly present, whereas $\mathrm{T}_{\mathrm{CM}}$ cells were scarcely detected. $\mathrm{T}_{\mathrm{SCM}}$ cells were also detected among SARS-CoV-2-specific MHC-I multimer ${ }^{+}$cells during the study period, but not among IAV- and CMV-specific cells (Fig. 4d). In particular, the frequency of $\mathrm{T}_{\mathrm{SCM}}$ cells among SARS-CoV-2specific MHC-I multimer ${ }^{+}$cells was high 60-125 DPSO.

A recent study has revealed two distinct subsets of $\mathrm{CCR}^{+}$stem cell-like progenitors: $\mathrm{CCR}^{+}{ }^{+} \mathrm{PD}-1^{-}{ }^{-}$TIGIT $^{-}$cells with stem cell-like features and CCR7 ${ }^{+} \mathrm{PD}-1^{+} \mathrm{TIGIT}^{+}$cells with exhausted traits ${ }^{23,24}$. Therefore, we compared the percentage of $\mathrm{PD}^{-}{ }^{-}{ }^{-}$TIGIT $^{-}$cells among MHC-I multimer ${ }^{+} \mathrm{CD}^{+}{ }^{+} \mathrm{T}_{\mathrm{SCM}}$ cells to the percentage among MHC-I multimer ${ }^{+} \mathrm{CD} 8{ }^{+} \mathrm{T}$ cells. We found that the frequency of $\mathrm{PD}-1^{-}$TIGIT $^{-}$cells was significantly higher among MHC-I multimer ${ }^{+} \mathrm{CD}^{+}{ }^{+} \mathrm{T}_{\mathrm{SCM}}$ cells (Fig. 4e), confirming that SARSCoV-2-specific $\mathrm{T}_{\mathrm{SCM}}$ cells are bona fide stem-like memory cells.

We performed additional experiments to examine the detailed stem cell-like properties of SARS-CoV-2-specific $\mathrm{T}_{\mathrm{SCM}}$ cells. We used PBMCs obtained from 110 to 140 DPSO $(n=3)$ and sorted SARS-CoV-2-specific $\mathrm{AIM}^{+}\left(\mathrm{CD}_{137}{ }^{+}\right) \mathrm{CD}^{+}{ }^{+} \mathrm{T}_{\mathrm{SCM}}$ (CCR7 $^{+}$ $\mathrm{CD}^{2} \mathrm{RA}^{+} \mathrm{CD}^{-} 5^{+}$) cells. Next, we labeled them with CellTrace Violet (CTV), stimulated them with the S OLP pool for 7 days, and assessed their proliferation. We observed robust proliferation of SARS-CoV-2-specific $\mathrm{T}_{\mathrm{SCM}}$ cells (Supplementary Fig. 6a). We also examined whether SARS-CoV-2-specific $\mathrm{T}_{\mathrm{SCM}}$ cells differentiate into other memory subsets following stimulation with the $S$ OLP pool for 7 days and found that $\mathrm{T}_{\mathrm{SCM}}$ cells differentiated into diverse memory subsets, comprising $\sim 72 \% \mathrm{~T}_{\mathrm{EM}}, 10 \% \mathrm{~T}_{\mathrm{EMRA}}$, $7 \% \mathrm{~T}_{\mathrm{CM}}$, and $10 \% \mathrm{~T}_{\mathrm{SCM}}$ cells (Supplementary Fig. $6 \mathrm{~b}$ ). We also evaluated the self-renewal capacity of $\mathrm{T}_{\mathrm{SCM}}$ cells following stimulation with IL-15, a homeostatic cytokine, for 5 days and observed robust proliferation of SARS-CoV-2-specific $\mathrm{CD}^{+}$and $\mathrm{CD}^{+} \mathrm{T}_{\mathrm{SCM}}$ cells (Supplementary Fig. 6c). Based on our results that SARS-CoV-2-specific $\mathrm{T}_{\mathrm{SCM}}$ cells exhibit a potent proliferative capacity and multipotency to reconstitute diverse memory subsets, we anticipate that SARS-CoV-2-specific memory T cells can robustly proliferate and differentiate into effector cells upon re-exposure to SARS-CoV-2.
Polyfunctionality and proliferation capacity are preserved in long-term SARS-CoV-2-specific T cells. As we observed the generation of SARS-CoV-2-specific $\mathrm{T}_{\mathrm{SCM}}$ cells with self-renewal capacity and multipotency, we aimed to examine the kinetics of the polyfunctionality of SARS-CoV-2-specific T cells during the study period. To this end, we performed intracellular cytokine staining of IFN- $\gamma$, IL-2, TNF, and CD107a following stimulation with OLP pools of $S, M$, and $\mathrm{N}$ and analyzed the polyfunctionality of $\mathrm{CD}^{+}$and $\mathrm{CD}^{+}{ }^{+}$cells (Fig. 5a). We defined polyfunctional cells as cells exhibiting positivity for $\geq 2$ effector functions. Among SARS-CoV-2-specific $\mathrm{CD} 4^{+}$and $\mathrm{CD} 8^{+} \mathrm{T}$ cells, the average proportion of polyfunctional cells was $25-40 \%$ and $30-50 \%$, respectively, 60 DPSO, and was maintained until 254 DPSO (Fig. 5b). We found no significant difference in the frequency of polyfunctional cells among SARS-CoV-2-specific $\mathrm{CD}_{4}^{+}$and CD8 + T cells between T1 (31-99 DPSO), T2 (100-199 DPSO), and T3 ( $\geq 200$ DPSO; Fig. 5c). Preserved polyfunctionality among SARSCoV-2-specific CD4 ${ }^{+}$and $\mathrm{CD} 8^{+} \mathrm{T}$ cells was also observed when polyfunctionality was evaluated according to the number of positive effector functions (Fig. 5d).

We also examined the antigen-induced proliferation capacity of long-term SARS-CoV-2-specific memory T cells. We performed CTV dilution assays and Ki-67 staining using PBMCs obtained after 200 DPSO $\mathrm{CD}^{+}$and $\mathrm{CD}^{+} \mathrm{T}$ cells exhibited a significant proliferative response following in vitro stimulation with the $S$ OLP pool (Fig. 5e), indicating that SARS-CoV-2-specific memory $\mathrm{T}$ cells elicit rapid recall responses upon viral re-exposure.

Considering preserved polyfunctionality and proliferation capacity of SARS-CoV-2-specific memory $\mathrm{T}$ cells, the current data indicate that memory $\mathrm{T}$ cells contribute to protective immunity against re-infection even 10 months after the primary infection.

SARS-CoV-2-specific $\mathrm{T}$ cell memory is maintained regardless of disease severity. To determine the effect of disease severity at the time of acute infection on the generation of long-term $(\geq 200$ DPSO) SARS-CoV-2-specific T cell memory, we compared longterm SARS-CoV-2-specific $\mathrm{T}$ cell responses between the asymptomatic/mild patient group and the moderate/severe/critical patient group. In this comparison, we analyzed the magnitude of the response as evaluated by IFN- $\gamma$ ELISpot and AIM assays, and the proportion of polyfunctional cells and $\mathrm{T}_{\mathrm{SCM}}$ cells among SARS-CoV-2-specific memory $T$ cells. We found no significant difference in any of the parameters between the two groups (Supplementary Fig. 7a-d).

A recent study showed that 6 months after infection, asymptomatic individuals have lower SARS-CoV-2-specific T cell responses than individuals who recovered from symptomatic infection $^{25}$. Another study reported similar SARS-CoV-2-specific $\mathrm{T}$ cell responses between asymptomatic individuals and symptomatic COVID-19 patients, but that the $\mathrm{T}$ cell responses may decline more rapidly in asymptomatic individual ${ }^{26}$. Therefore, we compared long-term $(\geq 200$ DPSO) T cell memory between the asymptomatic and symptomatic groups. We could not find a 
a

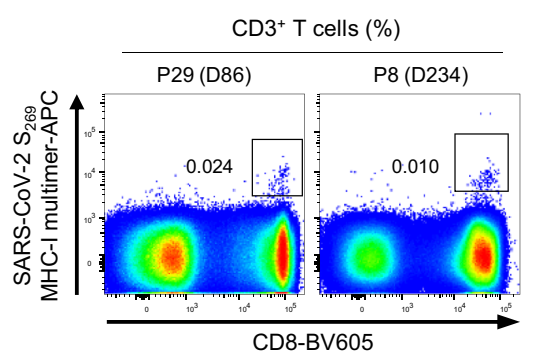

b

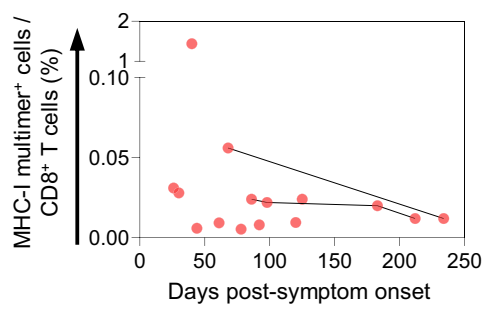

d

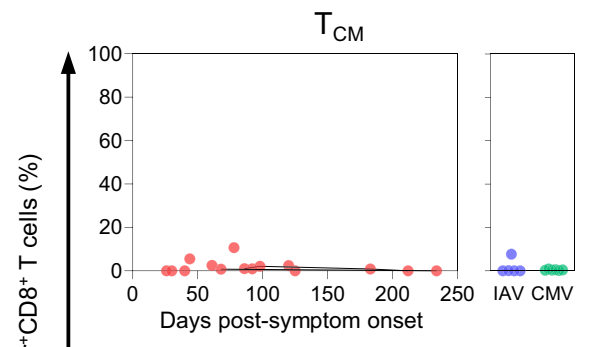

TEMRA

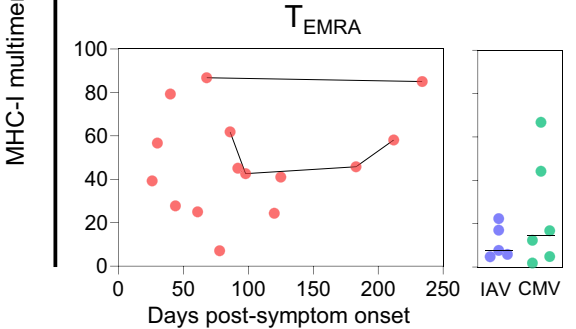

- SARS-CoV-2 MHC-I multimer ${ }^{+}$cells
C

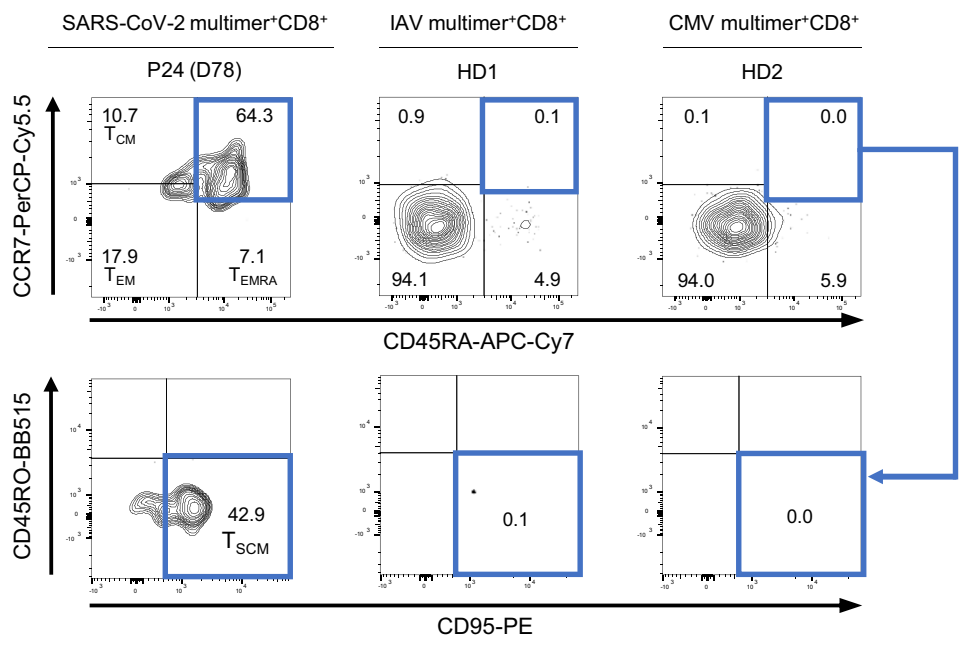

e

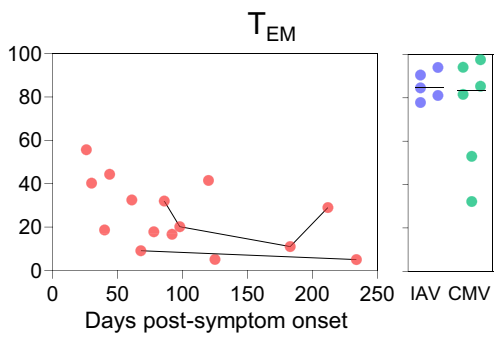

SARS-CoV-2-specific CD8 ${ }^{+} T_{\mathrm{SCM}}$ SARS-CoV-2-specific CD8 ${ }^{+} T$

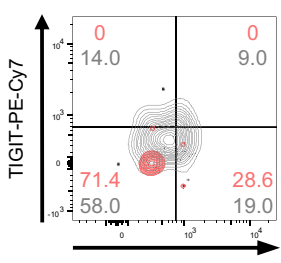

$\mathrm{T}_{\mathrm{SCM}}$

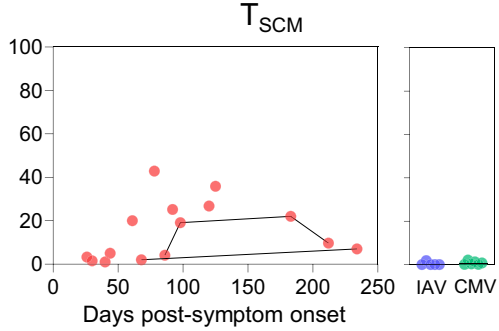

CMV MHC-I multimer ${ }^{+}$cells

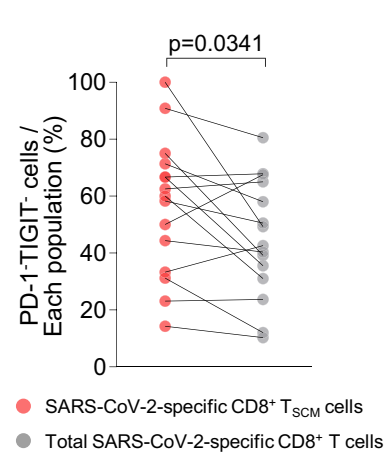

Fig. 4 Frequency and differentiation status of SARS-CoV-2-specific MHC-I multimer ${ }^{+} \mathbf{T}$ cells. PBMC samples $(n=15)$ from individuals with SARS-CoV2 infection $(n=11)$ were analyzed by flow cytometry. a Representative flow cytometry plots showing the ex vivo detection of SARS-CoV-2 S 269 multimer ${ }^{+} \mathrm{CD}^{+}{ }^{+} \mathrm{T}$ cells in the gate of $\mathrm{CD}^{+} \mathrm{T}$ cells. $\mathbf{b}$ Scatter plot showing the relationship between DPSO and the frequency of SARS-CoV-2 $\mathrm{S}_{269}$ multimer ${ }^{+}$cells among total $\mathrm{CD}^{+} \mathrm{T}$ cells. Samples from the same patient are connected by solid lines. The expression of CCR7, CD45RA, and CD95 was analyzed in SARS-CoV-2 $\mathrm{S}_{269}$ multimer ${ }^{+} \mathrm{CD} 8^{+}$T cells. IAV MP 58 multimer ${ }^{+}(n=5)$ and $\mathrm{CMV}$ pp65495 multimer ${ }^{+}(n=6)$ cells from the PBMCs of healthy donors were also analyzed. Representative flow cytometry plots (c) show the proportion of the indicated subsets among multimer cells, and scatter plots (d) show the relationship between DPSO and the proportion of the indicated subsets among SARS-CoV- $2 \mathrm{~S}_{269}$ multimer ${ }^{+}$cells. Samples from the same patient are connected by solid lines. Summary data showing the proportion of the indicated subsets among IAV multimer ${ }^{+}$and $\mathrm{CMV}_{\text {multimer }}{ }^{+}$cells are also presented (d). Horizontal lines represent median. e A representative flow cytometry plot (upper) and summary data (lower) showing the percentage of PD-1-TIGIT- cells among SARS-CoV-2 $\mathrm{S}_{269}$ multimer ${ }^{+} \mathrm{CD} 8{ }^{+} \mathrm{T}_{\mathrm{SCM}}$ cells and total SARS-CoV-2 $\mathrm{S}_{269}$ multimer ${ }^{+} \mathrm{CD} 8^{+} \mathrm{T}$ cells. Statistical analysis was performed using the two-sided Wilcoxon signed-rank test (e).

significant difference in the number of IFN- $\gamma$ spots between the two groups (Supplementary Fig. 8). In addition, when we performed subgroup analyses of the asymptomatic/mild group and moderate/severe/critical group, we found no significant differences in the number of IFN- $\gamma$ spots or the frequencies of $\mathrm{AIM}^{+}$cells among T1 (31-99 DPSO), T2 (100-199 DPSO), and T3 ( $\geq 200$ DPSO) in either group (Supplementary Fig. 9). From these results, we conclude that SARS-CoV-2-specific $\mathrm{T}$ cell memory is successfully maintained regardless of the severity of COVID-19.

\section{Discussion}

Memory $\mathrm{T}$ cells play a crucial role in viral clearance during reinfection, but the longevity and differentiation status of SARSCoV-2-specific memory T cells among COVID-19 convalescent patients remain unclear. In the present study, we demonstrated that SARS-CoV-2-specific memory $\mathrm{T}$ cell responses were maintained in COVID-19 convalescent patients 10 months postinfection regardless of the disease severity. Notably, we found that SARS-CoV-2-specific $\mathrm{T}_{\mathrm{SCM}}$ cells were successfully developed, indicating that SARS-CoV-2-specific T cell memory may be long- 
a
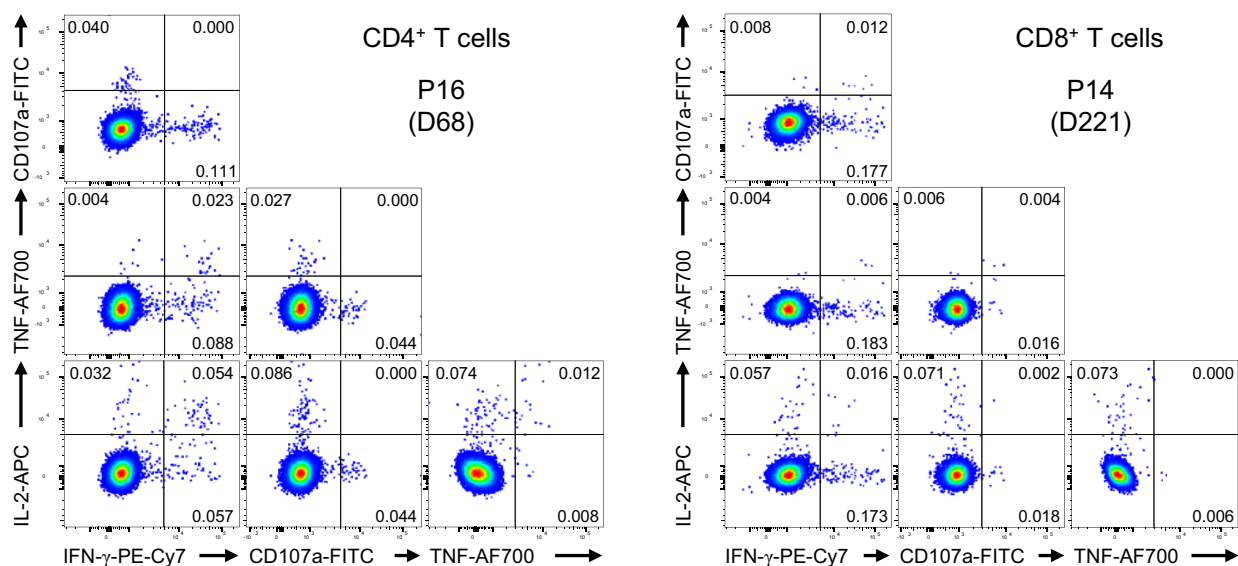

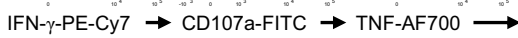

b $S$

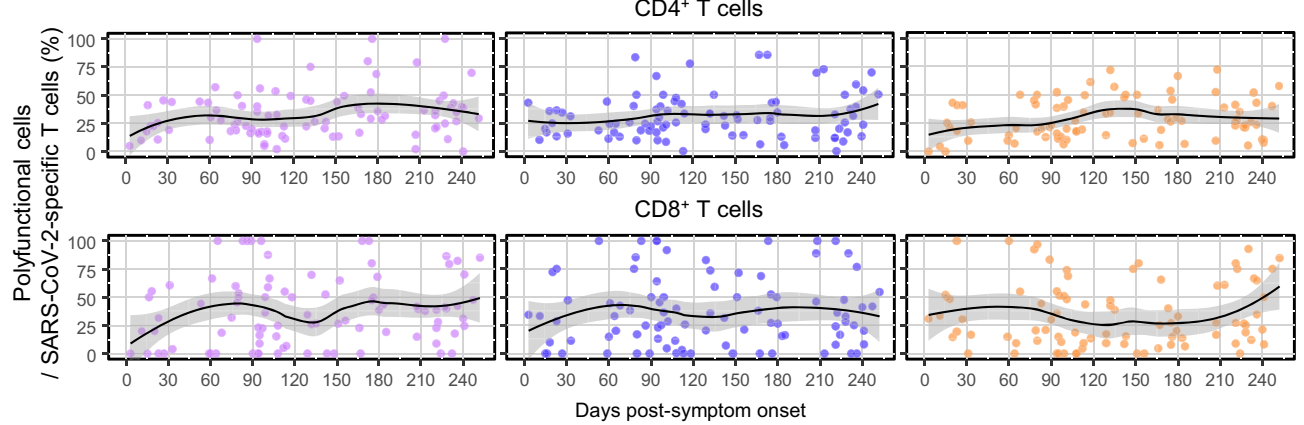

C
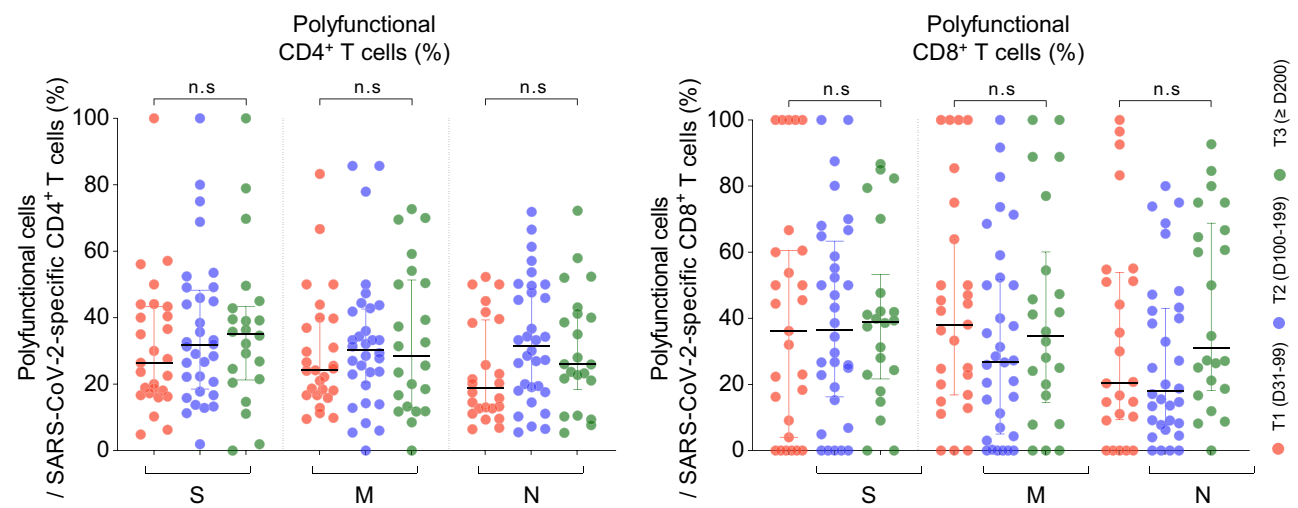

d

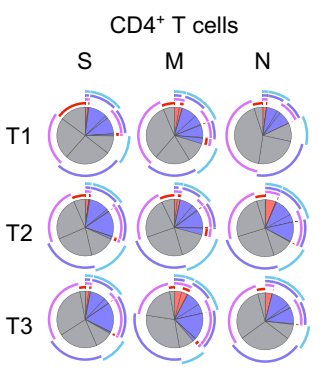

Arc: type of function $\square \mathrm{CD}_{107 \mathrm{a}^{+}} \square \mathrm{IFN}-\mathrm{\gamma}^{+} \square \mathrm{IL}-2^{+} \square \mathrm{TNF}^{+}$

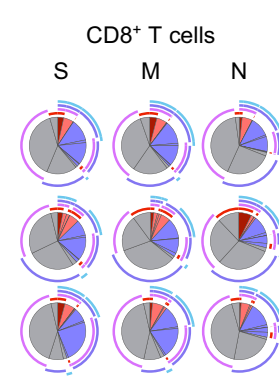

Pie: \# of functions $\square 4 \square 3 \square 2 \square 1$

lasting in COVID-19 convalescent patients. These findings were supported by the SARS-CoV-2-specific T cells from PBMCs obtained after 200 DPSO exhibiting sustained polyfunctionality and proliferation capacity. Our results may fill a gap in understanding $\mathrm{T}$ cell memory responses after recovery from SARSCoV-2 infection.

e

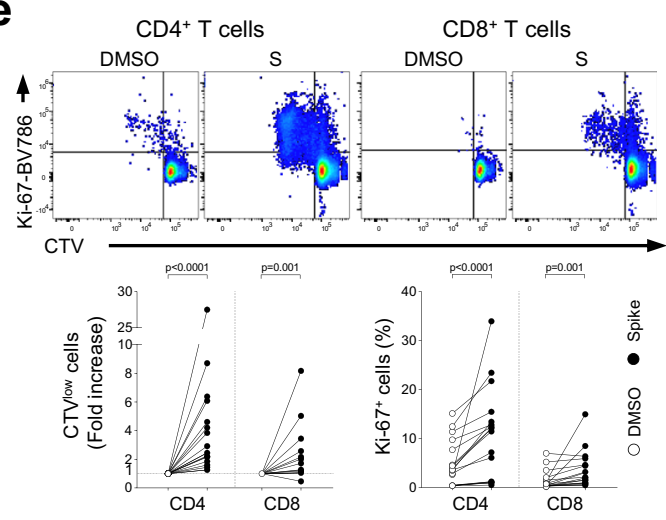

Recent studies suggest critical roles of $\mathrm{T}$ cells in the clearance of SARS-CoV-2 and protection from developing severe COVID-19. In particular, it has been shown that coordination of adaptive immune responses, including $\mathrm{CD}^{+} \mathrm{T}$ cell, $\mathrm{CD}^{+} \mathrm{T}$ cell, and antibody responses, is essential for controlling COVID-1920. Notably, peak disease severity has been shown to inversely correlate with the 
Fig. 5 Polyfunctionality and proliferation capacity of SARS-CoV-2-specific T cells. PBMC samples $(n=90)$ from individuals with SARS-CoV-2 infection $(n=39)$ were stimulated with OLPs of $\mathrm{S}, \mathrm{M}$, or $\mathrm{N}(1 \mu \mathrm{g} / \mathrm{mL})$ for $6 \mathrm{~h}$. Intracellular cytokine staining was performed to examine the frequency of polyfunctional cells exhibiting positivity for $\geq 2$ effector functions among SARS-CoV-2-specific CD4+ and CD8 ${ }^{+} \mathrm{T}$ cells. a Representative flow cytometry plots showing the frequency of polyfunctional cells among CD4+ (left) and CD8+ (right) T cells. b Scatter plots showing the relationship between DPSO and the frequency of polyfunctional cells among SARS-CoV-2-specific CD4+ (upper) or CD8 ${ }^{+}$(lower) T cells. The black line is a LOESS smooth nonparametric function, and the gray shading represents the $95 \%$ confidence interval. c The fraction of polyfunctional cells among SARS-CoV-2-specific $\mathrm{CD}^{+}$(left) or CD8 ${ }^{+}$(right) T cells was compared between T1 ( $n=17,31-99$ DPSO), T2 ( $n=39,100-199$ DPSO), and T3 ( $n=25, \geq 200$ DPSO). Data are presented as median and IQR. $\mathbf{d}$ Pie charts showing the fraction of cells positive for a given number of functions among SARS-CoV-2-specific CD4+ (left) or $\mathrm{CD}^{+}$(right) T cells. Each arc in the pie chart represents the indicated function. e CTV-labeled PBMCs $(n=18)$ obtained after 200 DPSO were stimulated with S OLP pool $(1 \mu \mathrm{g} / \mathrm{mL})$ for $120 \mathrm{~h}$ and the frequency of CTVlow and Ki-67+ cells among CD4 ${ }^{+}$and CD8 ${ }^{+} \mathrm{T}^{+}$cells was analyzed.

Representative plots (upper) and summary data (lower) are presented. Statistical analysis was performed using the two-sided Kruskal-Wallis test with Dunns' multiple comparisons test (c) or the two-sided Wilcoxon signed-rank test (e). n.s, not significant.

frequency of SARS-CoV-2-specific $\mathrm{CD}^{+}$and $\mathrm{CD} 8^{+} \mathrm{T}$ cells instead of SARS-CoV-2 antibody titers ${ }^{20}$. In another study, $\mathrm{T}$ cell responses were detected among COVID-19 convalescent patients without detectable SARS-CoV-2 IgG ${ }^{27}$. In a rhesus macaque model, CD8depleted convalescent animals exhibited limited viral clearance in the respiratory tract upon SARS-CoV-2 re-challenge, suggesting that $\mathrm{CD}^{+}{ }^{+} \mathrm{T}$ cells contribute to viral clearance during SARS-CoV-2 re-infection ${ }^{10}$. Collectively, these studies strongly demonstrate a protective role of $\mathrm{T}$ cells in COVID-19.

Currently, we do not have exact information on how long adaptive immune memory lasts in COVID-19 convalescent patients. Whether antibody responses to SARS-CoV-2 wane over time in patients who have recovered from COVID-19 remains controversial $^{28-30}$. Previous studies on SARS-CoV-1 and MERS$\mathrm{CoV}$ infection have shown that $\mathrm{T}$ cell responses were more enduring compared to antibody responses ${ }^{12,13}$. A recent study detected SARS-CoV-1-specific T cell responses 17 years after infection ${ }^{6}$. Similarly, slow decay of SARS-CoV-2-specific memory $\mathrm{T}$ cells is expected. In the present study, we demonstrated the maintenance of SARS-CoV-2-specific memory $\mathrm{T}$ cell responses in COVID-19 convalescent patients over 10 months post-infection using a battery of $\mathrm{T}$ cell assays. Given that vaccination programs for prophylaxis of SARS-CoV-2 infection are being launched worldwide, another question is how long memory $\mathrm{T}$ cells elicited by vaccination will last. Vaccine-induced memory $\mathrm{T}$ cells may differ in phenotype and durability from infection-induced memory $\mathrm{T}$ cells, which should be addressed in future studies.

Although this current study showed the persistence of SARSCoV-2-specific $\mathrm{T}$ cell responses in COVID-19 convalescent patients, another recent study suggested a reduction in SARS-CoV2-specific $\mathrm{CD}^{+}$and $\mathrm{CD}^{+} \mathrm{T}$ cell responses with a half-life of 3-5 months ${ }^{14}$. This discrepancy can be explained by multiple factors. First, the demographic characteristics of the study cohorts were different. Asians comprised $98 \%$ of our study population but only $7 \%$ in the other study. SARS-CoV-2-specific $\mathrm{T}$ cell responses may vary depending on ethnicity. A demographic difference may also explain why $\mathrm{T}$ cell memory is maintained in the current study regardless of disease severity but declined more rapidly in asymptomatic individuals in a previous study ${ }^{26}$. Second, geographic factors also need to be considered, particularly in relation to previous exposure to other coronaviruses. Le Bert et al. ${ }^{6}$ demonstrated that SARS-CoV-2-reactive $\mathrm{T}$ cell responses are present in $50 \%$ of unexposed individuals in Singapore. Interestingly, they showed that the $\mathrm{T}$ cell epitopes found among unexposed donors were conserved among animal beta-coronaviruses rather than common-cold coronaviruses. Third, the clinical characteristics of the patients, including peak disease severity, were different between the two studies. Finally, the other study relied on a single type of $\mathrm{T}$ cell assay, whereas our study examined $\mathrm{T}$ cell memory using multiple types of assays, including IFN- $\gamma$ ELISpot, AIM, ICS, and proliferation assays. More recent studies support our results by demonstrating the persistence of SARS-CoV-2-specific $\mathrm{T}$ cell responses in COVID-19 convalescent patients ${ }^{31,32}$.

A series of studies have reported the existence of SARS-CoV-2reactive $\mathrm{T}$ cell responses among unexposed individuals, suggesting that memory $\mathrm{T}$ cells induced by previous $\mathrm{ccCoV}$ infection are cross-reactive to SARS-CoV-2 proteins ${ }^{5,33-36}$. Therefore, in the present study, we could not distinguish de novo primed $\mathrm{T}$ cells by SARS-CoV-2 infection from pre-existing, cross-reactive ccCoVspecific T cells. However, we could selectively examine de novo primed SARS-CoV-2-specific T cells by staining with an HLAA*02 multimer loaded with SARS-CoV-2 S269 (YLQPRTFLL) peptide. This epitope peptide has a low degree of homology with ccCoVs, including OC43, HKU1, 229E, and NL63 ${ }^{22,23}$. In future studies of SARS-CoV-2-specific T cell responses, cross-reactive epitope peptides and SARS-CoV-2-specific epitope peptides will need to be used separately ${ }^{34}$.

Among distinct subsets of memory $\mathrm{T}$ cells, $\mathrm{T}_{\mathrm{SCM}}$ cells possess a superior ability for self-renewal, memory recall responses, and multipotency to reconstitute diverse memory subsets ${ }^{15}$. Therefore, long-term $\mathrm{T}$ cell memory relies on the successful generation of $\mathrm{T}_{\mathrm{SCM}}$ cells $^{16}$. Previous studies showed that long-lasting YFVspecific $\mathrm{CD}^{+} \mathrm{T}$ cells resemble $\mathrm{T}_{\mathrm{SCM}}$ cells ${ }^{17,18}$. We and others have also suggested the generation of SARS-CoV-2-specific $\mathrm{T}_{\mathrm{SCM}}$ cells in the convalescent phase of COVID-19 on the basis of the expression of CCR7 and CD45RA ${ }^{8,23}$. However, these studies on COVID-19 patients did not examine the definitive marker of $\mathrm{T}_{\mathrm{SCM}}$ cells, CD95. In the present study, we delineated the kinetics of $\mathrm{T}_{\mathrm{SCM}}$ cells using both AIM assays and MHC-I multimer staining and observed the successful generation of $\mathrm{T}_{\mathrm{SCM}}$ cells in COVID-19 convalescent patients. In line with these findings, we also found sustained polyfunctionality and proliferation capacity, suggesting efficient memory recall responses. A recent study has proposed that $\mathrm{CCR}^{+}$stem-like progenitor cells are composed of two separate populations, which are distinguished by PD-1 and TIGIT expression ${ }^{24}$. We demonstrated that PD-1 and TIGIT are rarely expressed in SARS-CoV-2-specific $\mathrm{T}_{\mathrm{SCM}}$ cells, indicating that SARS-CoV-2-specific $\mathrm{T}_{\mathrm{SCM}}$ cells are not exhausted-like progenitors, but bona fide stem-like memory cells.

Polyfunctional T cells, which exert multiple effector functions simultaneously, play a critical role in host protection against viral infection $^{37-39}$. For example, polyfunctional $\mathrm{CD}^{+} \mathrm{T}$ cells are preserved in human immunodeficiency virus-infected long-term non-progressors ${ }^{38}$. In addition, polyfunctional $\mathrm{T}$ cell responses are associated with effective control of hepatitis $\mathrm{C}$ virus $(\mathrm{HCV})^{39}$. It has also been reported that virus-specific polyfunctional $\mathrm{T}$ cells can be successfully developed by immunization with vaccinia virus $^{40}$ and an HCV vaccine ${ }^{41}$. Collectively, polyfunctional memory $\mathrm{T}$ cells control viral infection more efficiently than monofunctional $\mathrm{T}$ cells. Therefore, generation of polyfunctional memory $\mathrm{T}$ cells following natural infection or vaccination is expected to confer protective immunity. In this regard, the 
sustained polyfunctionality of long-term SARS-CoV-2-specific $\mathrm{T}$ cells observed in our study is highly suggestive of long-lasting protective immunity in COVID-19 convalescent patients.

In the current study, we conducted a comprehensive analysis of SARS-CoV-2-specific memory $\mathrm{T}$ cell responses over 10 months post-infection. Considering that the current study was based on random sample collection, the conclusion needs to be validated by a study based on a systematic blood collection protocol. Despite this limitation, our current analysis provides valuable information regarding the longevity and differentiation of SARS$\mathrm{CoV}-2$-specific memory $\mathrm{T}$ cells elicited by natural infection. These data add to our basic understanding of memory $\mathrm{T}$ cell responses in COVID-19, which aids in establishing an effective vaccination program and epidemiological measurement.

\section{Methods}

Patients and specimens. In this study, 101 patients with PCR-confirmed SARSCoV-2 infection were enrolled from Ansan Hospital and Chungbuk National University Hospital, Republic of Korea. Peripheral blood was obtained from all patients with SARS-CoV-2 infection. In seven asymptomatic patients, the date of the first admission was regarded as seven DPSO because the date of the first admission among symptomatic patients was an average seven DPSO. We also used PBMCs obtained before the COVID-19 pandemic from eight healthy donors. This study was reviewed and approved by the institutional review board of all participating institutions (Chungbuk National University Hospital: 2020-03-036-001; Korea University Ansan Hospital: 2020AS0122) and conducted according to the principles of the Declaration of Helsinki. Informed consent was obtained from all donors and patients.

PBMCs were isolated by density gradient centrifugation using Lymphocyte Separation Medium (Corning). After isolation, the cells were cryopreserved in fetal bovine serum (FBS; Corning) with 10\% dimethyl sulfoxide (DMSO; SigmaAldrich) until use.

\section{Ex vivo IFN- $\boldsymbol{\gamma}$ enzyme-linked immunospot assay. Plates with hydrophobic} polyvinylidene difluoride membrane (Millipore) were coated with $2 \mu \mathrm{g} / \mathrm{mL}$ antihuman monoclonal IFN- $\gamma$ coating antibody (clone 1-D1K, Mabtech) overnight at $4{ }^{\circ} \mathrm{C}$. The plates were washed with sterile phosphate-buffered saline (PBS) and blocked with $1 \%$ bovine serum albumin (Bovogen) for $1 \mathrm{~h}$ at room temperature (RT). 700,000 PBMCs were seeded per well and stimulated with $1 \mu \mathrm{g} / \mathrm{mL}$ OLP pools spanning SARS-CoV-2 S, M, and N proteins (Miltenyi Biotec) for $24 \mathrm{~h}$ at $37^{\circ}$ C. We used $10 \mu \mathrm{g} / \mathrm{mL}$ phytohemagglutinin as a positive control and an equimolar amount of DMSO as a negative control. Plates were washed with $0.05 \%$ Tween-PBS (Junsei Chemical) and incubated with $0.25 \mu \mathrm{g} / \mathrm{mL}$ biotinylated anti-human monoclonal IFN- $\gamma$ antibody (clone 7-B6-1, Mabtech) for $2 \mathrm{~h}$ at RT. After washing, streptavidin-alkaline phosphatase (Invitrogen) was added sequentially. Precipitates were detected with AP color reagent (Bio-Rad) and the reaction stopped by rinsing with distilled water. Spot-forming units were quantified using an automated ELISpot reader (AID). To quantify SARS-CoV-2-specific responses, spots in the negative control wells were subtracted from the OLP-stimulated wells.

Multi-color flow cytometry. Cells were stained with fluorochrome-conjugated antibodies for specific surface markers for $10 \mathrm{~min}$ at RT. Dead cells were excluded using LIVE/DEAD red fluorescent reactive dye (Invitrogen). In intracellular staining experiments, cells were fixed and permeabilized using the FoxP3 staining buffer kit (Invitrogen), and then stained for intracellular markers for $30 \mathrm{~min}$ at $4^{\circ}$ C. The following monoclonal antibodies were used for multi-color flow cytometry: anti-hCD3 BV510 (clone UCHT1, cat\# 563109, 1:100), anti-hCD3 BV786 (clone UCHT1, cat\# 565491, 1:100), anti-hCD4 (clone RPA-T4, cat\# 562358, 1:100), antihCD4 FITC (clone RPA-T4, cat\# 555346, 1:100), anti-hCD4 PerCP ${ }^{\mathrm{mm}} \mathrm{Cy} 5.5$ (clone RPA-T4, cat\# 560650, 1:100), anti-hCD8 APC-Cy7 (clone SK1, cat\# 560179, 1:100), anti-hCD8 BV605 (clone SK1, cat\# 564116, 1:100), anti-hCD8 BV711 (clone RPAT8, cat\# 563677, 1:100), anti-hCD14 PE-CF594 (clone $\mathrm{M} \varphi \mathrm{P} 9$, cat\# 562335, 1:100), anti-hCD19 PE-CF594 (clone HIB19, cat\# 562294, 1:100), anti-hCD27 BV510 (clone L128, cat\# 563092, 1:100), anti-hCD45RO BB515 (clone UCHL1, cat\# 564529, 1:100), anti-hCD69 PE-Cy7 (clone FN50, cat\# 557745, 1:100), anti-hCD95 PE (clone DX2, cat\# 555674, 1:100), anti-hCD107a FITC (clone H4A3, cat\# 555800, 1:100), anti-hCD137 APC (clone 4B4-1, cat\# 550890, 1:100), anti-hCD137 BV421 (clone 4B4-1, cat\# 564091, 1:100), anti-hCD154 APC (clone TRAP1, cat\# 555702 , 1:100), anti-hIFN- $\gamma$ PE-Cy7 (clone 4S.B3, cat\# 557844, 1:100), anti-hIL-2 APC (clone MQ1-17H12, cat\# 554567, 1:100), anti-hKi-67 BV786 (clone B56, cat\# 563756, 1:100), and anti-hTNF AF700 (clone Mab11, cat\# 557996, 1:100) from BD Biosciences; anti-hCCR7 PerCP ${ }^{\text {sm }}$ Cy5.5 (clone G043H7, cat\# 353220, 1:100), antihCD3 APC (clone HIT3a, cat\# 300312, 1:100), anti-hCD8 FITC (clone RPA-T8, cat\# 301050, 1:100), anti-hCD45RA APC-Cy7 (clone HI100, cat\# 304128, 1:100), anti-hCD137 PE (clone 4B4-1, cat\# 309804, 1:100), anti-hOX40 BV421 (clone BerACT35, cat\# 350014, 1:100), and anti-hPD-1 BV421 (clone EH12.2H7, cat\# $329920,1: 100$ ) from BioLegend; anti-hTIGIT PE-Cy7 (clone MBSA43, cat\# 25-
9500-42, 1:100) from Invitrogen. The following multimers were used for multicolor flow cytometry: GILGFVFTL (IAV MP ${ }_{58}$ ) HLA-A*0201 APC Dextramer (cat\# WB2161, 1:20) and NLVPMVATV (CMV pp65 ${ }_{495}$ ) HLA-A*0201 APC Dextramer (cat\# WB2132, 1:20) from Immudex; YLQPRTFLL (SARS-CoV-2 $\mathrm{S}_{269}$ ) HLA-A*0201 APC Pentamer (cat\# 4339, 1:20) from Proimmune. Multi-color flow cytometry was performed using an LSR II instrument with FACSDiva (BD Biosciences) and the data analyzed in FlowJo software (FlowJo LLC). The details of fluorochrome-conjugated MHC-I multimers and monoclonal antibodies used in this study are described in Supplementary Table 3.

Activation-induced marker assay. PBMCs were blocked with $0.5 \mu \mathrm{g} / \mathrm{mL}$ antihuman CD40 mAb (clone HB14, Miltenyi Biotec) in RPMI 1640 supplemented with $10 \%$ FBS and $1 \%$ penicillin and streptomycin (Welgene) for $15 \mathrm{~min}$ at $37^{\circ} \mathrm{C}$. The cells were then cultured in the presence of $1 \mu \mathrm{g} / \mathrm{mL}$ SARS-CoV-2 OLP pools and $1 \mu \mathrm{g} / \mathrm{mL}$ anti-human CD28 and CD49d mAbs (clone L293 and L25, respectively, BD Biosciences) for $24 \mathrm{~h}$. Stimulation with an equal concentration of DMSO in PBS was performed as a negative control.

MHC-I multimer staining. PBMCs were stained with multimers for $15 \mathrm{~min}$ at RT and washed twice. Additional surface markers were stained using the protocols described above.

Stimulation for intracellular cytokine staining. PBMCs were cultured in the presence of SARS-SoV-2 OLP pools and $1 \mu \mathrm{g} / \mathrm{mL}$ anti-human CD28 and CD49d mAbs for $6 \mathrm{~h}$ at $37^{\circ} \mathrm{C}$. Brefeldin A (GolgiPlug, BD Biosciences) and monensin (GolgiStop, BD Biosciences) were added $1 \mathrm{~h}$ after the initial stimulation. Polyfunctionality of the stimulated cells was analyzed with SPICE software.

Proliferation assays. PBMCs were labeled using the CellTrace ${ }^{\mathrm{Tn}}$ Violet Cell Proliferation Kit (Invitrogen) at a concentration of $1.0 \times 10^{6}$ cells $/ \mathrm{mL}$ for $20 \mathrm{~min}$ at $37^{\circ}$ C. We then added $1 \%$ FBS-PBS to the cells for $5 \mathrm{~min}$ at RT to quench unbound dyes. Cells were washed and cultured in RPMI 1640 containing 10\% FBS and 1\% penicillin-streptomycin at a concentration of 500,000 cells per well in the presence of $1 \mu \mathrm{g} / \mathrm{mL}$ SARS-CoV-2 S peptide pools and $1 \mu \mathrm{g} / \mathrm{mL}$ anti-human CD28 and CD49d mAbs for $120 \mathrm{~h}$. Stimulation with an equal concentration of DMSO in PBS was performed as a negative control. After incubation, cells were harvested and stained with antibodies for analysis by flow cytometry.

$\mathbf{T}_{\text {SCM }}$ cell sorting and functional analysis. AIM assays were performed with SARS-CoV-2 S OLP stimulation, and $\mathrm{CD}^{+} \mathrm{T}$ cells were magnetically enriched using CD8 MicroBeads (Miltenyi Biotec). $\mathrm{AIM}^{+}\left(\mathrm{CD} 137^{+}\right) \mathrm{CD}^{+} \mathrm{T}_{\mathrm{SCM}}\left(\mathrm{CCR} 7^{+}\right.$ CD45RA ${ }^{+} \mathrm{CD}^{+} 5^{+}$) cells were further sorted using FACS ARIA II cell sorter (BD Biosicences) with purity of $>95 \%$. Sorted $\mathrm{CD}^{+} \mathrm{T}_{\mathrm{SCM}}$ cells were labeled with CTV and cultured with $1 \mu \mathrm{g} / \mathrm{mL}$ SARS-CoV-2 S OLPs in the presence of $1 \mu \mathrm{g} / \mathrm{mL}$ antihuman CD28 and CD49d mAbs for 7 days. Irradiated autologous CD8 ${ }^{-}$cells were used as feeder cells. Proliferation of $\mathrm{T}_{\mathrm{SCM}}$ cells and memory phenotypes of the $\mathrm{T}_{\mathrm{SCM}}$ cell progeny were assessed by flow cytometry.

For evaluation of the self-renewal capacity of $\mathrm{T}_{\mathrm{SCM}}$ cells, CTV-labeled PBMCs were cultured in the presence of recombinant human IL-15 (25 ng/mL; PeproTech) for $120 \mathrm{~h}$. After incubation, AIM assays were performed with SARS-CoV-2 S OLP stimulation for the detection of SARS-CoV-2 S-specific $\mathrm{T}_{\mathrm{SCM}}$ cells. Proliferation of SARS-CoV-2 S-specific $\mathrm{CD}^{+}$and $\mathrm{CD}^{+}{ }^{+} \mathrm{T}_{\mathrm{SCM}}$ cells was assessed by flow cytometry.

Enzyme-linked immunosorbent assay. For the measurement of anti-SARS-CoV2 RBD IgG levels in plasma samples, SARS-CoV-2-Spike S1-RBD IgG and IgM ELISA Detection Kit (GenScript) was used according to the manufacturer's instruction. For the measurement of SARS-CoV-2 neutralizing activities of plasma samples, SARS-CoV-2 Surrogate Virus Neutralization Detection Kit (GenScript) was used according to the manufacturer's instruction. The percent of the neutralizing activity was calculated with the following equation.

$$
\text { Neutralization }(\%)=\left(1-\frac{\text { Sample absorbance }}{\text { Negative control absorbance }}\right) \times 100 \%
$$

Data quantification and statistical analysis. Data were calculated as background-subtracted data. Background-subtracted data were derived by subtracting the value after DMSO stimulation. When three stimuli were combined, the value after each stimulation was combined and we subtracted triple the value derived from DMSO stimulation.

Statistical analyses were performed using GraphPad Prism version 9 for Windows (GraphPad Software). Significance was set at $p<0.05$. The Wilcoxon signed-rank test was used to compare data between two paired groups. The Mann-Whitney $U$ test was used in comparison between two unpaired groups. In addition, the Kruskal-Wallis test with Dunns' multiple comparisons test was used to compare non-parametric data between multiple unpaired groups. To assess the significance of correlation, the Spearman correlation test was used. In crosssectional analyses, a non-parametric local regression (LOESS) function was 
employed with 95\% confidence interval. LOESS analysis was performed using $\mathrm{R}^{42}$ with following packages: dplyr, tidyr, ggplot2, tidyverse, ggthemes, and svglite.

Reporting summary. Further information on research design is available in the Nature Research Reporting Summary linked to this article.

\section{Data availability}

All data supporting the findings of this study are available within the main manuscript and the supplementary files or provided upon reasonable request. Raw data corresponding to all the main and supplementary figures are included in the Source Data file. Source data are provided with this paper.

Received: 26 January 2021; Accepted: 18 June 2021; Published online: 30 June 2021

\section{References}

1. Huang, C. et al. Clinical features of patients infected with 2019 novel coronavirus in Wuhan, China. Lancet 395, 497-506 (2020).

2. World Health Organization. Weekly Epidemiological Update on COVID-19. 4 May 2021 https://www.who.int/publications/m/item/weekly-epidemiologicalupdate-on-covid-19---4-may-2021 (2021).

3. Lee, J. S. et al. Immunophenotyping of COVID-19 and influenza highlights the role of type I interferons in development of severe COVID-19. Sci. Immunol. 5, eabd1554 (2020).

4. Lee, J. S. \& Shin, E. C. The type I interferon response in COVID-19: implications for treatment. Nat. Rev. Immunol. 20, 585-586 (2020).

5. Grifoni, A. et al. Targets of T cell responses to SARS-CoV-2 coronavirus in humans with COVID-19 disease and unexposed individuals. Cell $\mathbf{1 8 1}$ 1489-1501 (2020). e15.

6. Le Bert, N. et al. SARS-CoV-2-specific T cell immunity in cases of COVID-19 and SARS, and uninfected controls. Nature 584, 457-462 (2020).

7. Peng, Y. et al. Broad and strong memory CD4 $(+)$ and CD8(+) T cells induced by SARS-CoV-2 in UK convalescent individuals following COVID-19. Nat. Immunol. 21, 1336-1345 (2020).

8. Sekine, T. et al. Robust $\mathrm{T}$ cell immunity in convalescent individuals with asymptomatic or mild COVID-19. Cell 183, 158-168 (2020). e14.

9. Rodda, L. B. et al. Functional SARS-CoV-2-specific immune memory persists after mild COVID-19. Cell 184, 169-183 (2020). e17.

10. McMahan, K. et al. Correlates of protection against SARS-CoV-2 in rhesus macaques. Nature 590, 630-634 (2020).

11. $\mathrm{Ng}, \mathrm{O}$. W. et al. Memory $\mathrm{T}$ cell responses targeting the SARS coronavirus persist up to 11 years post-infection. Vaccine 34, 2008-2014 (2016).

12. Zhao, J. X. et al. Recovery from the Middle East respiratory syndrome is associated with antibody and T cell responses. Sci. Immunol. 2, eaan5393 (2017).

13. Tang, F. et al. Lack of peripheral memory B cell responses in recovered patients with severe acute respiratory syndrome: a six-year follow-up study. $J$. Immunol. 186, 7264-7268 (2011).

14. Dan, J. M. et al. Immunological memory to SARS-CoV-2 assessed for up to 8 months after infection. Science 371, eabf4063 (2021).

15. Gattinoni, L. et al. A human memory T cell subset with stem cell-like properties. Nat. Med. 17, 1290-1297 (2011).

16. Gattinoni, L., Speiser, D. E., Lichterfeld, M. \& Bonini, C. T memory stem cells in health and disease. Nat. Med. 23, 18-27 (2017).

17. Fuertes Marraco, S. A. et al. Long-lasting stem cell-like memory CD8+ T cells with a naive-like profile upon yellow fever vaccination. Sci. Transl. Med. 7, 282ra248 (2015).

18. Akondy, R. S. et al. Origin and differentiation of human memory CD8 T cells after vaccination. Nature 552, 362-367 (2017).

19. National Institutes of Health. COVID-19 treatment guidelines panel. Coronavirus Disease 2019 (COVID-19) Treatment Guidelines. https://www. covid19treatmentguidelines.nih.gov (2020).

20. Moderbacher, C. R. et al. Antigen-specific adaptive immunity to SARS-CoV-2 in acute COVID-19 and associations with age and disease severity. Cell 183, 996-1012 (2020). e19.

21. Morou, A. et al. Altered differentiation is central to HIV-specific CD4(+) T cell dysfunction in progressive disease. Nat. Immunol. 20, 1059-1070 (2019).

22. Shomuradova, A. S. et al. SARS-CoV-2 epitopes are recognized by a public and diverse repertoire of human T cell receptors. Immunity 53, 1245-1257 (2020). e5.

23. Rha, M. S. et al. PD-1-expressing SARS-CoV-2-specific CD8(+) T cells are not exhausted, but functional in patients with COVID-19. Immunity 54, 44-52 (2021). e3.

24. Galletti, G. et al. Two subsets of stem-like CD8(+) memory T cell progenitors with distinct fate commitments in humans. Nat. Immunol. 21, 1552-1562 (2020).
25. Zuo, J. M. et al. Robust SARS-CoV-2-specific T cell immunity is maintained at 6 months following primary infection. Nat. Immunol. https://doi.org/10.1038/ s41590-021-00902-8 (2021).

26. Le Bert, N. et al. Highly functional virus-specific cellular immune response in asymptomatic SARS-CoV-2 infection. J. Exp. Med. 218, e20202617 (2021)

27. Schwarzkopf, S. et al. Cellular immunity in COVID-19 convalescents with PCR-confirmed infection but with undetectable SARS-CoV-2-specific IgG. Emerg. Infect. Dis. 27, https://doi.org/10.3201/2701.203772 (2020).

28. Ibarrondo, F. J. et al. Rapid decay of anti-SARS-CoV-2 antibodies in persons with mild Covid-19. N. Engl. J. Med. 383, 1085-1087 (2020).

29. Isho, B. et al. Persistence of serum and saliva antibody responses to SARS CoV-2 spike antigens in COVID-19 patients. Sci. Immunol. 5, eabe5511 (2020).

30. Long, Q. X. et al. Clinical and immunological assessment of asymptomatic SARS-CoV-2 infections. Nat. Med. 26, 1200-1204 (2020).

31. Sherina, N. et al. Persistence of SARS-CoV-2-specific B and T cell responses in convalescent COVID-19 patients 6-8 months after the infection. Medicines 2, 281-295 (2021). e4.

32. Bilich, T. et al. T cell and antibody kinetics delineate SARS-CoV-2 peptides mediating long-term immune responses in COVID-19 convalescent individuals. Sci. Transl. Med. 13, eabf7517 (2021).

33. Mateus, J. et al. Selective and cross-reactive SARS-CoV-2 T cell epitopes in unexposed humans. Science 370, 89-94 (2020).

34. Nelde, A. et al. SARS-CoV-2-derived peptides define heterologous and COVID-19-induced T cell recognition. Nat. Immunol. 22, 74-85 (2020).

35. Woldemeskel, B. A. et al. Healthy donor T cell responses to common cold coronaviruses and SARS-CoV-2. J. Clin. Invest. 130, 6631-6638 (2020).

36. Braun, J. et al. SARS-CoV-2-reactive T cells in healthy donors and patients with COVID-19. Nature 587, 270-274 (2020).

37. Almeida, J. R. et al. Superior control of HIV-1 replication by CD8+ T cells is reflected by their avidity, polyfunctionality, and clonal turnover. J. Exp. Med. 204, 2473-2485 (2007).

38. Betts, M. R. et al. HIV nonprogressors preferentially maintain highly functional HIV-specific CD8+ T cells. Blood 107, 4781-4789 (2006).

39. Ciuffreda, D. et al. Polyfunctional HCV-specific T-cell responses are associated with effective control of HCV replication. Eur. J. Immunol. 38, 2665-2677 (2008)

40. Precopio, M. L. et al. Immunization with vaccinia virus induces polyfunctional and phenotypically distinctive CD8(+) T cell responses. J. Exp. Med. 204, 1405-1416 (2007).

41. Park, S. H. et al. Successful vaccination induces multifunctional memory Tcell precursors associated with early control of hepatitis $\mathrm{C}$ virus. Gastroenterology 143, 1048-1060 (2012). e4.

42. R Core Team (2021). R: a language and environment for statistical computing. R Foundation for Statistical Computing, Vienna, Austria. https://www.Rproject.org/.

\section{Acknowledgements}

This work was supported by the Samsung Science and Technology Foundation under Project Number SSTF-BA1402-51, and the Mobile Clinic Module Project funded by KAIST.

\section{Author contributions}

J.H.J., M.-S.R., H.W.J., W.S.C., and E.-C.S. designed the research. H.K.C., J.H.J., H.S., D. W.P., H.W.J., and W.S.C. collected clinical specimens. J.H.J., M.-S.R., and M.S. performed experiments. J.H.J., M.-S.R., S.-H.P., and E.-C.S. analyzed the results. J.H.J., M.-S. R. and E.-C.S. wrote the manuscript.

\section{Competing interests}

The authors declare no competing interests.

\section{Additional information}

Supplementary information The online version contains supplementary material available at https://doi.org/10.1038/s41467-021-24377-1.

Correspondence and requests for materials should be addressed to H.W.J., W.S.C. or E.-C.S.

Peer review information Nature Communications thanks Antonio Bertoletti, Rajiv Khanna and Jincun Zhao for their contribution to the peer review of this work. Peer reviewer reports are available.

Reprints and permission information is available at http://www.nature.com/reprints

Publisher's note Springer Nature remains neutral with regard to jurisdictional claims in published maps and institutional affiliations. 
(c) (i) Open Access This article is licensed under a Creative Commons Attribution 4.0 International License, which permits use, sharing, adaptation, distribution and reproduction in any medium or format, as long as you give appropriate credit to the original author(s) and the source, provide a link to the Creative Commons license, and indicate if changes were made. The images or other third party material in this article are included in the article's Creative Commons license, unless indicated otherwise in a credit line to the material. If material is not included in the article's Creative Commons license and your intended use is not permitted by statutory regulation or exceeds the permitted use, you will need to obtain permission directly from the copyright holder. To view a copy of this license, visit http://creativecommons.org/ licenses/by/4.0/.

(C) The Author(s) 2021 